\title{
Effect of Thermoelastic Properties of the Pyrope-Almandine Solid Solutions on the Entrapment Pressure of Garnet-Related Elastic Geobarometer
}

\section{OPEN ACCESS}

Edited by:

Lidong Dai,

Institute of geochemistry (CAS), China

Reviewed by:

Dayong Tan,

The Institute of Advanced Science

Facilities, China

Dongzhou Zhang,

University of Hawaii at Manoa,

United States

*Correspondence:

Dawei Fan

fandawei@vip.gyig.ac.cn

Specialty section:

This article was submitted to Earth and Planetary Materials,

a section of the journal

Frontiers in Earth Science

Received: 11 December 2021

Accepted: 21 December 2021

Published: 26 January 2022

Citation:

Li B, Jiang J, Xu J, Tkachev SN, Ye Z,

Huang S, Guo W, Zeng Y,

Prakapenka VB, Fan D and Zhou W

(2022) Effect of Thermoelastic

Properties of the Pyrope-Almandine

Solid Solutions on the Entrapment

Pressure of Garnet-Related

Elastic Geobarometer.

Front. Earth Sci. 9:833405.

doi: 10.3389/feart.2021.833405

\author{
Bo $L_{i}^{1,2,3}$, Junjie Jiang ${ }^{4}$, Jingui $X u^{5}$, Sergey N. Tkachev ${ }^{6}$, Zhilin Ye ${ }^{2,3}$, Shijie Huang ${ }^{2,3}$, \\ Weihua Guo ${ }^{1}$, Yongjun Zeng ${ }^{1}$, Vitali B. Prakapenka ${ }^{6}$, Dawei Fan ${ }^{2 *}$ and Wenge Zhou ${ }^{2}$
}

${ }^{1}$ Research Institute of Petroleum Exploration \& Development-Northwest (NWGI), PetroChina, Lanzhou, China, ${ }^{2}$ Key Laboratory of High-Temperature and High-Pressure Study of the Earth's Interior, Institute of Geochemistry, Chinese Academy of Sciences, Guiyang, China, ${ }^{3}$ University of Chinese Academy of Sciences, Beijing, China, ${ }^{4}$ Basic Geological Survey Institute of Jiangxi Geological Survey Institute, Nanchang, China, ${ }^{5}$ Hawail Institute of Geophysics and Planetology, School of Ocean and Earth Science and Technology, University of Hawaii at Manoa, Honolulu, HI, United States, ${ }^{6}$ Center for Advanced Radiation Sources, University of Chicago, Chicago, IL, United States

The pyrope (Prp)-almandine (Alm) solid solutions are the most fundamental garnet components on the Earth, and both the quartz inclusions in garnet (QuiG) barometry and the garnet inclusions in diamond barometry need to be constrained by the thermoelastic parameters of Prp-Alm solid solution garnets. Here, we report the thermoelastic properties of a series of synthetic Prp-Alm solid solutions based on the high-pressure and high-temperature $(H P-H T)$ in situ synchrotron single-crystal $\mathrm{x}$-ray diffraction (SCXRD) experiments up to $\sim 20 \mathrm{GPa}$ and $700 \mathrm{~K}$, using diamond anvil cell (DAC). Fitting the SCXRD data by the Birch-Murnaghan equation of state (BM-EoS) and the thermal-pressure EoS, we obtain the thermoelastic parameters of Prp-Alm solid solution garnets, including bulk modulus $\left(K_{0}\right)$, its pressure derivative $\left(K^{\prime}{ }_{0}\right)$, and the thermal expansion coefficient $\left(\alpha_{0}\right)$. The $K_{0}$ along the Prp-Alm solid solution changes linearly with Prp content within their uncertainties and can be expressed by $K_{0}(\mathrm{GPa})=$ 181.0(8) $-0.11(1) X_{\text {prp }}\left(R^{2}=0.91, X_{\text {prp }}\right.$ is the Prp mole fraction and $K^{\prime}{ }_{0}$ fixed at 4). Our result indicates that the compressibility of the Prp-Alm solid solution increases with the increasing Prp content. However, the thermal expansion coefficient of Prp-Alm solid solution at ambient pressure shows a non-linear trend with Prp content and can be expressed by $\alpha_{0}$ $\left(10^{-5} \mathrm{~K}^{-1}\right)=2.7(1)+3.0(5) X_{\operatorname{Prp}}-3.2(4) X_{\operatorname{Prp}}^{2}\left(R^{2}=0.985\right)$. It shows that the Prp-Alm solid solution with intermediate composition has a larger thermal expansion coefficient than those close to the endmembers at ambient conditions. Furthermore, we also evaluated the influence of thermoelastic properties of the Prp-Alm solid solution on the entrapment pressure $\left(P_{e}\right)$ estimation for two types of elastic geobarometers. Our results indicate that the garnet component may significantly influence entrapment pressure, and among the thermoelastic parameters of garnet, the thermal expansion coefficient has the main effect on the estimation of $P_{e}$.

Keywords: pyrope-almandine solid solution, elastic geobarometer, equation of state, high pressure and high temperature, diamond anvil cell 


\section{INTRODUCTION}

Diamond is the only direct sample obtained from inaccessible portions of Earth (Nestola et al., 2019) and the subduction zone metamorphism controls many global geochemical cycles and the lithosphere (Ashley et al., 2016). Estimating the pressure and temperature of these minerals or rocks provides fundamental data for studying many such geological processes, but their determination remains extremely controversial (Bebout, 2007; Tajčmanová et al., 2021). To date, various methods have been developed to address the geological history of rocks. Previous studies have used mineral-mineral equilibrium based on Gibbs free energy minimization or partitioning major or trace elements between phases to recover these geological processes (De Capitani and Petrakakis, 2010; Holland and Powell, 2011). Despite advances in analytical techniques, geothermobarometers still suffer from problems due to alteration processes, such as the erasure of peak metamorphic mineral assemblages (e.g., Korsakov et al., 2009; Jamtveit et al., 2016), chemical re-equilibration, diffusion, and kinetic limitations (e.g., Anzolini et al., 2019; Gonzalez et al., 2019). Additionally, part of the difficulty in determining the pressure of rocks is the lack of typical pressure-dependent mineral equilibria, especially for the diamond-inclusion system (Ashley et al., 2016; Nestola et al., 2017).

Ideally, geobarometers should yield accurate pressure estimates using only commonly found minerals and not be susceptible to significant resetting during exhumation. Recently, an alternative method based on the mechanical equilibrium between entrapped mineral inclusions (e.g., quartz and garnet) and host mineral (e.g., garnet and diamond) has received significant attention and could vastly expand the range of barometers available to petrologists (e.g., Enami et al., 2007; Kohn, 2014; Milani et al., 2015; Cisneros et al., 2020). Inclusions encapsulated in host minerals such as garnet or diamond have different elastic properties; they produce a residual pressure $\left(P_{\text {inc }}\right)$ following exhumation, thereby allowing us to determine the entrapment pressure (Rosenfeld and Chase, 1961; Zhang, 1998). The $P_{\text {inc }}$ and the equations of state (EoS) of the hostinclusion system can be used to calculate unique $P-T$ curves (called isomekes) along which the pressure of the host and the inclusion are equal despite the changes in $P-T$ conditions. Detailed discussions of this application are given by Angel et al. (2015) and Gonzalez et al. (2019).

Much of the previous work has focused on the factors affecting the calculation accuracy of the elastic geobarometer, such as the viscosity/plasticity relaxation properties of the inclusions (Zhong et al., 2020), the elastic anisotropy of minerals (Murri et al., 2018; Mazzucchelli et al., 2019), and the non-ideal geometry of inclusions (Mazzucchelli et al., 2018). Moreover, precisely determining the $P_{\text {inc }}$ in inclusions has attracted many studies, as measured by $\mathrm{x}$-ray diffractometry (Angel et al., 2014b) or Raman spectroscopy (Enami et al., 2007; Korsakov et al., 2009; Ashley et al., 2016; Murri et al., 2018; Bonazzi et al., 2019). However, researchers rarely explored the effect of thermoelastic parameters of minerals in entrapment pressure $\left(P_{e}\right)$ calculations, which is crucial to improving elastic geobarometry precision
(Angel et al., 2015; Moulas et al., 2020). Only Angel et al. (2015) considered the influence of thermoelastic parameters of diamond in determining the pressure of formation of diamondinclusion systems. Moreover, as garnet rarely has a homogeneous composition, Moulas et al. (2020) considered the possible propagation of errors caused by the uncertainty of garnet composition in entrapment pressure $\left(P_{e}\right)$ calculations. Therefore, in this study, we evaluated the influence of the thermoelastic parameters of the concerned minerals on the calculated results of the two types of elastic geobarometers, garnet (inclusion)-diamond (host) system and quartz (inclusion)-garnet (host) system (QuiG). The garnet-diamond system is very appropriate for estimating the formation pressure of diamond because the garnet is the most abundant occurring inclusion mineral in the diamond (Milani et al., 2015). Similarly, QuiG is also suitable for geobarometers because quartz is highly compressible relative to garnet, and the garnet host can maintain a large stress difference caused by changes in $P-T$ conditions (Ashley et al., 2016). In these two types of elastic geobarometers, diamond and quartz are generally virtually pure endmember, and their thermoelastic parameters have been accurately determined (Angel et al., 2015; Angel et al., 2017a). However, the effect of composition of garnet on its thermoelastic parameters is still not very clear (Fan et al., 2017; Fan et al., 2018; Xu et al., 2019).

Garnet has cubic symmetry with $I a \overline{3} d$. The structure of garnet $\mathrm{X}_{3}^{2+} \mathrm{Y}_{2}^{3+} \mathrm{Si}_{3} \mathrm{O}_{12}$ consists of a mixed framework of corner-sharing $\mathrm{SiO}_{4}$ tetrahedra and $\mathrm{YO}_{6}$ octahedra, with $\mathrm{XO}_{8}$ triangular dodecahedron lying in between (Geiger, 2013) (Supplementary Figure S1). Garnet is flexible in accommodating a variety of cations with different ionic radii. Generally, divalent cations (e.g., $\mathrm{Mg}^{2+}, \mathrm{Fe}^{2+}, \mathrm{Ca}^{2+}, \mathrm{Mn}^{2+}$ ) occupy the X-site while trivalent cations (e.g., $\mathrm{Al}^{3+}, \mathrm{Fe}^{3+}, \mathrm{Cr}^{3+}$ ) occupy the $\mathrm{Y}$-site. Natural garnet usually does not exist as pure endmember components but form solid solutions through element partitioning (Fan et al., 2015). Summary and analysis of garnet compositions from the global major ultra-high-pressure metamorphic (UHPM) rocks and kimberlites indicate that garnet is mainly composed of pyrope ( $\operatorname{Prp}, \mathrm{Mg}_{3} \mathrm{Al}_{2} \mathrm{Si}_{3} \mathrm{O}_{12}$ ), almandine (Alm, $\mathrm{Fe}_{3} \mathrm{Al}_{2} \mathrm{Si}_{3} \mathrm{O}_{12}$ ), and grossular (Grs, $\mathrm{Ca}_{3} \mathrm{Al}_{2} \mathrm{Si}_{3} \mathrm{O}_{12}$ ) with some other endmember components like spessartine ( $\mathrm{Sps}, \mathrm{Mn}_{3} \mathrm{Al}_{2} \mathrm{Si}_{3} \mathrm{O}_{12}$ ) and andradite ( $\mathrm{Adr}, \mathrm{Ca}_{3} \mathrm{Fe}_{2}^{3+}$ $\mathrm{Si}_{3} \mathrm{O}_{12}$ ) (Zhang et al., 2010; Kosman et al., 2016; Riches et al., 2016; Broadwell et al., 2019; Cruciani et al., 2019; Xu et al., 2019; Liu et al., 2020). In addition, the modal abundance of Prp and Alm can reach $\sim 70 \%$ and become higher with the increasing of the metamorphic pressure.

Understanding the thermoelastic properties of garnet, especially the Prp-Alm solid solution, is not only important to model the structure of the subducted slab but also a primary step in quantifying the $P-T$ conditions of subduction and exhumation (Bass et al., 2008; Ashley et al., 2014). There are already extensive studies about the thermoelastic properties of Prp and Alm endmember component (Zhang L. et al., 1998; Gwanmesia et al., 2006; Fan et al., 2009; Li et al., 2011; Zou et al., 2012; Arimoto et al., 2015; Chantel et al., 2016; Hu et al., 2016; Fan et al., 2019b; Hartwig and Galkin, 2021). However, there is still a lack of tight constraints on the variation behavior of thermoelastic 
parameters developed when Prp-Alm solid solution is varying with composition (Takahashi and Liu, 1970; Huang and Chen, 2014; Milani et al., 2015). It is known that, for different mineral compositions, a variety of different cations incorporated in the garnets will affect their thermoelastic properties (Zhang et al., 1999; Kuang et al., 2019). In the 1970s, Takahashi and Liu (1970) conducted the pressure-volume $(P-V)$ EoS study on four garnet samples with different compositions (Prp $\operatorname{Pr}_{100}, \operatorname{Prp}_{60} \mathrm{Alm}_{31}$, $\operatorname{Prp}_{22} \mathrm{Alm}_{72}$, and $\mathrm{Alm}_{100}$ ) up to $32.8 \mathrm{GPa}$ using single-crystal $\mathrm{x}$-ray diffraction (SCXRD) and diamond anvil cell (DAC). They inferred that the bulk modulus $\left(K_{0}\right)$ of the Prp-Alm solid solution decreases with the increasing Alm content. However, the conclusion from Takahashi and Liu (1970) needs to be further verified because they did not use any gasket in their high-pressure SCXRD experiments, which may significantly influence their experimental results. Similarly, Huang and Chen (2014) also performed the $P-V$ EoS study on three synthetic Prp-Alm solid solutions $\left(\operatorname{Prp}_{83} \mathrm{Alm}_{17}\right.$, $\operatorname{Prp}_{54} \mathrm{Alm}_{46}$, and $\operatorname{Prp}_{30} \mathrm{Alm}_{70}$ ) up to $21 \mathrm{GPa}$ using in situ XRD combined with DAC, but obtained the opposite conclusion from Takahashi and Liu (1970), that is, the $K_{0}$ increases with the increasing Alm content. Furthermore, Huang and Chen (2014) also obtained the relationship between the $K_{0}$ of the Prp-Alm solid solutions and Alm content: $K_{0}=170.5(2.6)+0.12(4) X_{\mathrm{Alm}}\left(X_{\mathrm{Alm}}\right.$ is the mole fraction of Alm). Subsequently, Milani et al. (2015) studied the $P-V$ EoS on three synthetic Prp-Alm solid solutions $\left(\operatorname{Prp}_{100}\right.$, $\operatorname{Prp}_{60} \mathrm{Alm}_{40}$, and $\mathrm{Alm}_{100}$ ) and obtained the same conclusion as that of Huang and Chen (2014). Nevertheless, to date, the thermoelastic properties of the Prp-Alm solid solutions at simultaneous high-pressure and high-temperature $(H P-H T)$ conditions are still not entirely well constrained.

In this study, we selected eight synthetic Prp-Alm solid solution samples $\left(\operatorname{Prp}_{9} \mathrm{Alm}_{91}, \operatorname{Prp}_{23} \mathrm{Alm}_{76}, \operatorname{Prp}_{31} \mathrm{Alm}_{68}\right.$, $\operatorname{Prp}_{48} \mathrm{Alm}_{52}, \quad \operatorname{Prp}_{57} \mathrm{Alm}_{43}, \quad \operatorname{Prp}_{67} \mathrm{Alm}_{32}, \quad \operatorname{Prp}_{78} \mathrm{Alm}_{22}$, and $\operatorname{Prp}_{87} \mathrm{Alm}_{12}$ ) for the synchrotron SCXRD measurements up to $\sim 20 \mathrm{GPa}$ and four Prp-Alm solid solution samples $\left(\operatorname{Prp}_{14} \mathrm{Alm}_{86}\right.$, $\operatorname{Prp}_{31} \mathrm{Alm}_{68}, \operatorname{Prp}_{48} \mathrm{Alm}_{52}$, and $\operatorname{Prp}_{67} \mathrm{Alm}_{32}$ ) for the synchrotron SCXRD measurements up to $20 \mathrm{GPa}$ and $700 \mathrm{~K}$. Based on the obtained thermoelastic parameters of the systematic Prp-Alm solid solutions, we discussed the effects of composition $\left(\mathrm{Mg}^{2+}\right.$ $\mathrm{Fe}^{2+}$ substitution) on the thermoelastic parameters of Prp-Alm solid solutions. Finally, we used these results to calculate the $P_{\mathrm{e}}$ in two host-inclusion systems and discussed the effects of the thermoelastic parameters of Prp-Alm-rich garnet on the results of $P_{\mathrm{e}}$ calculations.

\section{SAMPLES AND EXPERIMENTAL METHODS}

The single crystals of Prp-Alm solid solutions $\left(\operatorname{Prp}_{9} \mathrm{Alm}_{91}\right.$, $\operatorname{Prp}_{14} \mathrm{Alm}_{86}, \operatorname{Prp}_{23} \mathrm{Alm}_{76}, \operatorname{Prp}_{31} \mathrm{Alm}_{68}, \operatorname{Prp}_{48} \mathrm{Alm}_{52}, \operatorname{Prp}_{57} \mathrm{Alm}_{43}$, $\operatorname{Prp}_{67} \mathrm{Alm}_{32}, \operatorname{Prp}_{78} \mathrm{Alm}_{22}$, and $\operatorname{Prp}_{87} \mathrm{Alm}_{12}$ ) used in this study were synthesized at $H P-H T$ conditions using a multi-anvil pressure apparatus (YJ-3000t) at the Institute of Geochemistry, Chinese Academy of Sciences, Guiyang, China. The detailed information about the garnet sample synthesis and subsequent compositional and structural analysis are described by Kuang et al. (2019). In general, with the increasing Alm content, the typical size of granular Prp-Alm crystals increases from $\sim 60 \mu \mathrm{m}$ to more than $100 \mu \mathrm{m}$. The Prp-Alm solid solutions with good euhedral crystals, high quality, and without inclusions were selected for the SCXRD experiments. We successively double-side polished our sample pieces to $\sim 20-30 \mu \mathrm{m}$ thickness, using the $3 \mathrm{M}$ diamond lapping films with grain size from coarse to a final $1 \mu \mathrm{m}$. The polished platelets were then cleaved into several square pieces of the desired size $(\sim 40-60 \mu \mathrm{m})$ for SCXRD experiments.

High pressure and room temperature $(H P-R T)$ SCXRD experiments were conducted on eight Prp-Alm solid solution samples using three short symmetrical DACs (cell-1: $\operatorname{Prp}_{9} \mathrm{Alm}_{91}$, $\operatorname{Prp}_{31} \mathrm{Alm}_{68}, \quad \operatorname{Prp}_{48} \mathrm{Alm}_{52} ;$ cell-2: $\operatorname{Prp}_{57} \mathrm{Alm}_{43}, \quad \operatorname{Prp}_{67} \mathrm{Alm}_{32}$, $\operatorname{Prp}_{78} \mathrm{Alm}_{22}$, and $\operatorname{Prp}_{87} \mathrm{Alm}_{12}$, and cell-3: $\operatorname{Prp}_{23} \mathrm{Alm}_{76}$ ). Rhenium ( $\mathrm{Re}$ ) gaskets of $\sim 250 \mu \mathrm{m}$ thickness were pre-indented to $\sim 65 \mu \mathrm{m}$ thickness using a pair of $500-\mu \mathrm{m}$ culet size diamond anvils. Subsequently, a $\sim 300-\mu \mathrm{m}$-diameter cylindrical hole was drilled in the pre-indented area as the sample chamber. The selected single-crystal platelets with diameters of $\sim 40-60 \mu \mathrm{m}$ were then placed into the sample chamber together with gold powder, which served as the pressure standard (Fei et al., 2007). The diffraction patterns of gold were collected before and after sample data collection for each pressure, and the average pressure values were used for the EoS fitting. A small ruby sphere of $\sim 10 \mu \mathrm{m}$ was also loaded into each DAC sample chamber and used as the pressure indicator during the neon gas-loading. The neon pressure medium was loaded into the sample chamber using the gas-loading system at GeoSoilEnviroCARS (GSECARS) (Rivers et al., 2008). After the neon gas loading, the diameter of the sample chamber was $\sim 220 \mu \mathrm{m}$.

HP-HT SCXRD experiments were carried out using an externally heated DAC (EHDAC) equipped with an alumina ceramic heater coiled with two Pt wires of $200 \mu \mathrm{m}$ in diameter and $48 \mathrm{~cm}$ length (Kantor et al., 2012; Fan et al., 2019a). A rhenium foil was used as the gasket material and pre-indented to $\sim 60 \mu \mathrm{m}$ thickness using a pair of diamond anvils with $500-\mu \mathrm{m}$ culet size and then a 300- $\mu$ m-diameter sample chamber was drilled at the center of pre-indentation. The selected singlecrystal platelets $\left(\operatorname{Prp}_{14} \mathrm{Alm}_{86}, \operatorname{Prp}_{31} \mathrm{Alm}_{68}, \operatorname{Prp}_{48} \mathrm{Alm}_{52}\right.$, and $\operatorname{Prp}_{67} \mathrm{Alm}_{32}$ ) with a diameter of $\sim 40 \mu \mathrm{m}$ were loaded into the sample chamber together with gold powder, which served as the pressure standard at $H P-H T$ conditions. For each $P-T$ point, the diffraction patterns of gold were collected before and after sample data collection, and the average pressure values were used. Likewise, a small ruby sphere of $\sim 10 \mu \mathrm{m}$ was loaded as the pressure indicator for the gas-loading with neon as the pressure transmitting medium using the GSECARS gasloading system. Heating was carried out by a resistanceheating system (Fan et al., 2010). A $\mathrm{Pt}_{90} \mathrm{Rh}_{10}-\mathrm{Pt}_{100}$ thermocouple was attached to one of the diamond surfaces, approximately $500 \mu \mathrm{m}$ away from its culet, and clad with a ceramic adhesive (Resbond 920) for temperature measurements (Kantor et al., 2012). To minimize temperature instability for each heating run, we first heated the sample chamber to an expected temperature and then kept it at this temperature for $15 \mathrm{~min}$. The temperatures of the sample chamber 


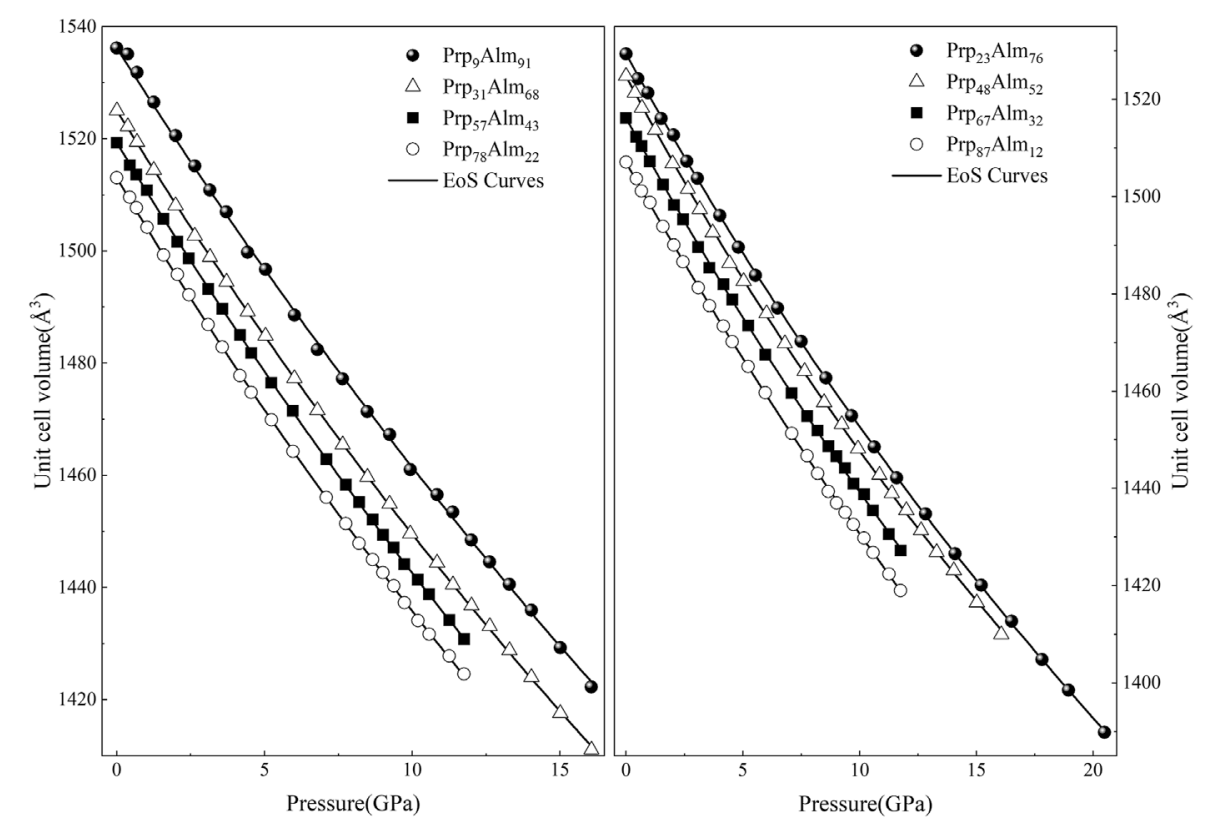

FIGURE 1 | Unit-cell volume compression of pyrope-almandine solid solution garnets at high pressure and room temperature in this study. The error bars of the data points are smaller than the symbols.

were actively stabilized within $\pm 1 \mathrm{~K}$ using the temperature-power feedback program with a remotely controlled Tektronix Keithley DC power supply during the experiments (Sinogeikin et al., 2006).

Both of the HP-RT and HP-HT synchrotron SCXRD experiments were conducted at the 13-BMD beamline of the GeoSoilEnviroConsortium for Advanced Radiation Sources (GSECARS) of Advanced Photon Source (APS), Argonne National Laboratory (ANL). An incident $x$-ray beam of $0.3344 \AA$ wavelength focused on a $3 \times 7 \mu \mathrm{m}^{2}$ area was used to determine the unit-cell volume of Prp-Alm solid solution samples in the DACs. Diffraction images were acquired on a stationary Perkin-Elmer area detector. Tilting and rotation of the detector and the sample-to-detector distance were calibrated using ambient $\mathrm{LaB}_{6}$ as the diffraction standard. Wide and stepped $\varphi$-rotation exposure were collected for the single-crystal samples at each loading run, with an exposure time of $2 \mathrm{~s} / \mathrm{deg}$. The $\varphi$-rotation (the opening angle of the DAC is $\pm 15^{\circ}$ ) axis was horizontal and perpendicular to the incident $\mathrm{x}$-ray direction. The diffraction images collected at each $P-T$ point were analyzed using the GSE_ADA/RSV software (Dera et al., 2013).

\section{RESULTS}

\section{Equations of State of Prp-Alm Solid Solutions at High Pressure and Room Temperature}

The unit-cell volumes change with pressure at room temperature for eight Prp-Alm solid solution garnets and are presented in Supplementary Table S1 and Figure 1, showing that the unit-cell volumes of Prp-Alm solid solution with increasing pressure garnets decrease systematically. Using the console program EosFit7c (Angel et al., 2014a; Gonzalez-Platas et al., 2016), the EoS parameters, including the room $P-T$ volume, the isothermal bulk modulus, and its pressure derivative of these Prp-Alm solid solutions, were refined by fitting their $P-V$ data using two different EoSs (BirchMurnaghan EoS and Vinet EoS).

Birch-Murnaghan equation of state. The $P-V$ relations of these Prp-Alm solid solutions have been determined by fitting their $H P-R T$ data to the third-order Birch-Murnaghan EoS, which is given in the following form:

$$
\begin{aligned}
& \mathrm{P}=(3 / 2) K_{0}\left[\left(\frac{V_{0}}{V}\right)^{7 / 3}-\left(\frac{V_{0}}{V}\right)^{5 / 3}\right] \times[1 \\
&\left.+\left(\frac{3}{4}\right)\left(K_{0}^{\prime}-4\right)\left[\left(\frac{V_{0}}{V}\right)^{2 / 3}-1\right]\right],
\end{aligned}
$$

where $V_{0}, K_{0}$, and $K_{0}^{\prime}$ are the unit-cell volume, isothermal bulk modulus, and its pressure derivative at ambient conditions, respectively. We obtained the $V_{0}, K_{0}$, and $K_{0}^{\prime}$ of Prp-Alm solid solutions, as shown in Table 1 . The refined value of $V_{0}$ was within $1 \sigma$ or so of the measured $V_{0}$ by XRD at ambient conditions, indicating the accuracy of the refined results (Angel, 2000). It can be found that the bulk moduli of Prp-Alm solid solutions gradually increase with increasing Alm content, especially when $K_{0}^{\prime}$ was fixed at 4 (Table 1). Furthermore, this trend is also in agreement with the conclusion of Huang and Chen (2014) and Milani et al. (2015). 
TABLE 1 | Bulk moduli and their first pressure derivative of garnets along the PrpAlm join.

\begin{tabular}{|c|c|c|c|c|}
\hline Composition & $V_{0}\left(\AA^{3}\right)$ & $K_{0}(\mathrm{GPa})$ & $K_{0}^{\prime}$ & Eos \\
\hline \multirow[t]{3}{*}{$\operatorname{Prp}_{9} A \mathrm{Im}_{91}$} & 1,537.3 (2) & $178.1(9)$ & 4 (fixed) & $\mathrm{BM}^{\mathrm{a}}$ \\
\hline & 1,537.6 (2) & $174(3)$ & $4.8(5)$ & \\
\hline & 1,537.6 (3) & $174(3)$ & $4.8(5)$ & Vinet $^{b}$ \\
\hline \multirow[t]{3}{*}{$\operatorname{Prp}_{23} \mathrm{Alm}_{76}$} & 1,529.0 (1) & $178.8(5)$ & 4 (fixed) & $\mathrm{BM}$ \\
\hline & 1,528.9 (1) & $181(2)$ & 3.7 (2) & \\
\hline & $1,528.9(1)$ & $181(2)$ & $3.8(3)$ & Vinet \\
\hline \multirow{3}{*}{$\operatorname{Prp}_{31} \mathrm{Alm}_{68}$} & 1,525.06 (2) & $177.9(4)$ & 4 (fixed) & $\mathrm{BM}$ \\
\hline & $1,525.06(2)$ & $177(1)$ & $4.2(3)$ & \\
\hline & $1,525.06(2)$ & $177(1)$ & $4.2(2)$ & Vinet \\
\hline \multirow[t]{3}{*}{$\operatorname{Prp}_{48} \mathrm{Alm}_{52}$} & $1,524.0(2)$ & $175.8(8)$ & 4 (fixed) & $\mathrm{BM}$ \\
\hline & 1,524.6 (2) & $167(2)$ & $5.7(3)$ & \\
\hline & $1,524.6(2)$ & $167(2)$ & $5.8(3)$ & Vinet \\
\hline \multirow[t]{3}{*}{$\operatorname{Prp}_{57} \mathrm{Alm}_{43}$} & $1,519.3(1)$ & $174.1(5)$ & 4 (fixed) & BM \\
\hline & 1,519.3 (2) & $174(2)$ & $4.0(4)$ & \\
\hline & 1,519.3 (2) & $174(2)$ & $4.0(4)$ & Vinet \\
\hline \multirow[t]{3}{*}{$\operatorname{Prp}_{67} \mathrm{Alm}_{32}$} & 1,516.1 (1) & $173.6(5)$ & 4 (fixed) & $\mathrm{BM}$ \\
\hline & 1,516.1 (2) & $172(2)$ & $4.2(4)$ & \\
\hline & 1,516.1 (2) & $172(1)$ & $4.3(4)$ & Vinet \\
\hline \multirow[t]{3}{*}{$\operatorname{Prp}_{78} \mathrm{Alm}_{22}$} & $1,513.04(3)$ & $171.4(3)$ & 4 (fixed) & $\mathrm{BM}$ \\
\hline & 1,513.05 (3) & 169 (2) & $4.5(4)$ & \\
\hline & 1,513.05 (3) & $169(2)$ & $4.6(4)$ & Vinet \\
\hline \multirow[t]{3}{*}{$\operatorname{Prp}_{87} \mathrm{Alm}_{12}$} & $1,507.4(1)$ & $172.6(5)$ & 4 (fixed) & $\mathrm{BM}$ \\
\hline & 1,507.3 (2) & $174(2)$ & 3.7 (4) & \\
\hline & 1,507.3 (2) & $174(2)$ & $3.7(4)$ & Vinet \\
\hline
\end{tabular}

${ }^{a} B M$ : Birch-Murnaghan EOS.

${ }^{b}$ Vinet: Vinet EOS.

Numbers in parentheses represent standard deviations.

Vinet equation of state. We also analyzed the $P-V$ data using the Vinet EoS (Vinet et al., 1986), which is derived from a "universal equation" for solids and is represented as follows:

$$
P(V)=3 K_{0} y^{-2}(1-y) \exp \left[\eta_{0}(1-y)\right],
$$

where $y=x^{1 / 3}, x=V / V_{0}$, and $\eta_{0}=(3 / 2)\left(K^{\prime} 0-1\right)$. Analyses of Equation 2 yielded $V_{0}, K_{0}$, and $K_{0}^{\prime}$ for the Prp-Alm solid solutions (Table 1), which are reasonably consistent with those derived by fitting to the Birch-Murnaghan EoS.

Supplementary Table S2 summarizes the bulk moduli and their pressure derivatives for Prp and Alm endmembers and their solid solutions determined with various experimental techniques. As shown in Supplementary Table S2, the $K_{0}$ values of Prp endmember from the literature range from 163.7 (17) to 175 (2) GPa. Among them, Milani et al. (2015) reported the least value (163.7 GPa) due to their largest $K_{0}^{\prime}$ value (6.4) than those of other studies (4.3-4.6). There is a trade-off between the bulk modulus and its pressure derivative, which negatively correlates (Gatta et al., 2011). So, we obtained the confidence ellipses of $K_{0}$ and $K_{0}^{\prime}$ for pyrope from previous XRD studies, as shown in Figure 2. From Figure 2, we can see that the previous XRD results of pyrope all fall within the $68.3 \%(1 \sigma)$ confidence interval, with mean values of 171 (8) GPa and 4 (2) for $K_{0}$ and $K_{0}^{\prime}$, respectively. Meanwhile, the obtained $K_{0}$ of pyrope [170.0 (2)-175 (2) GPa] by using Brillouin light spectroscopy (BLS) and ultrasonic interferometry (UI) methods are also consistent with the results from the XRD method (Supplementary Table S2 and Figure 2). For the Alm endmember, the $K_{0}$ value [172.6 (15) GPa] obtained by Milani et al. (2015) was also smaller than other XRD results [179 (3)-185 (3) $\mathrm{GPa}$. The main reason remains that the $K^{\prime}{ }_{0}$ value (5.6) obtained by Milani et al. (2015) is higher than those of other studies (4-4.2). Moreover, Arimoto et al. (2015) reported that the $K_{0}$ value [174.2 (12) GPa] of Alm endmember using the UI method is slightly smaller than the result [179 (3) GPa] using the XRD method.

As a comparison, until now, the previous EoS studies on the Prp-Alm solid solutions are relatively limited. Huang and Chen (2014) measured three synthetic Prp-Alm solid solutions $\left(\operatorname{Prp}_{83} \mathrm{Alm}_{17}, \operatorname{Prp}_{54} \mathrm{Alm}_{46}\right.$, and $\operatorname{Prp}_{30} \mathrm{Alm}_{70}$ ) by the XRD method up to 7,21 , and $19 \mathrm{GPa}$, respectively. With fixed $K^{\prime}{ }_{0}$ at 4.3 , the $K_{0}$ obtained for these three samples were 172 (4), 174 (2), and 183 (2) $\mathrm{GPa}$, respectively. Subsequently, Milani et al. (2015) reported a significantly smaller value [167.2 (17) GPa], also using the XRD method for synthetic $\operatorname{Prp}_{60} \mathrm{Alm}_{40}$. As a consequence, the previous experimental studies indicated that the $K_{0}$ range along the Prp-Alm solid solutions from Prp to Alm endmembers is expected to be 163.7 (1)-185 (3) GPa (Supplementary Table S2). Our results show that the bulk moduli of our eight Prp-Alm solid solutions (Table 1) are within this range. Because the bulk modulus and its pressure derivative have a negative correlation of bulk modulus and its pressure derivative, the $K_{0}^{\prime}$ is permanently fixed at 4 for the following discussion of the relationship between the bulk moduli of Prp-Alm solid solutions and their compositions. Figure 3 shows the bulk moduli of Prp-Alm solid solutions as a function of composition, and we can observe that the compressibilities of Prp-Alm solid solutions increase with increasing Prp concentrations. Furthermore, by linear fitting of the results in this study, the bulk moduli of the Prp-Alm solid solutions as a function of Prp content can be expressed by $K_{0}(\mathrm{GPa})=181.0$ (8)-0.11(1) $X_{\text {prp }}\left(R^{2}=0.91, K_{0}^{\prime}\right.$ fixed at 4$)$. It is worth noting that the $K_{0}$ of most previous studies are in harmony with our fitting line, except for Milani et al. (2015) (Figure 3). It may be attributed to the

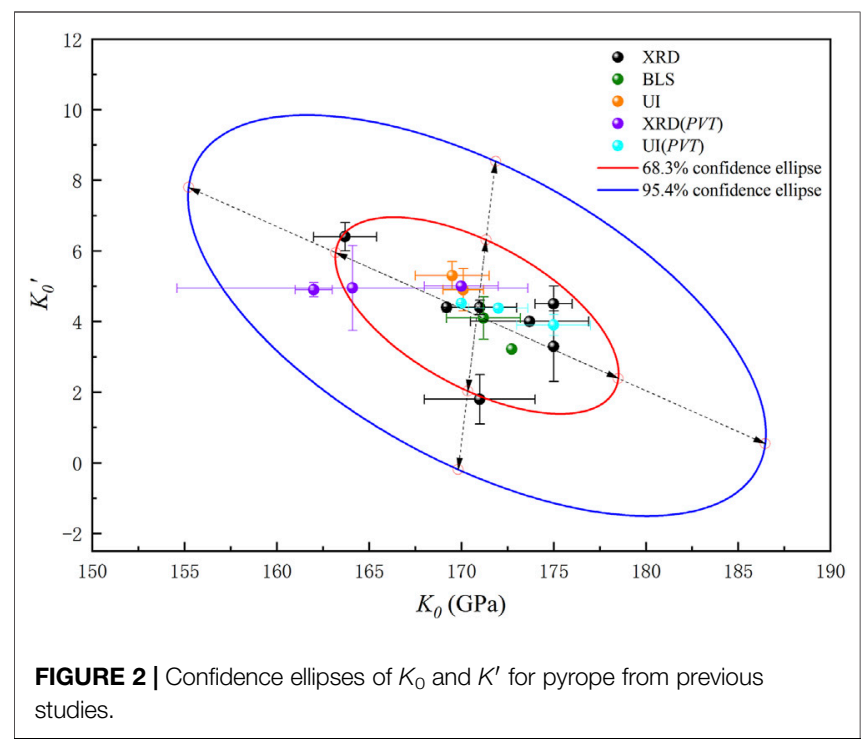




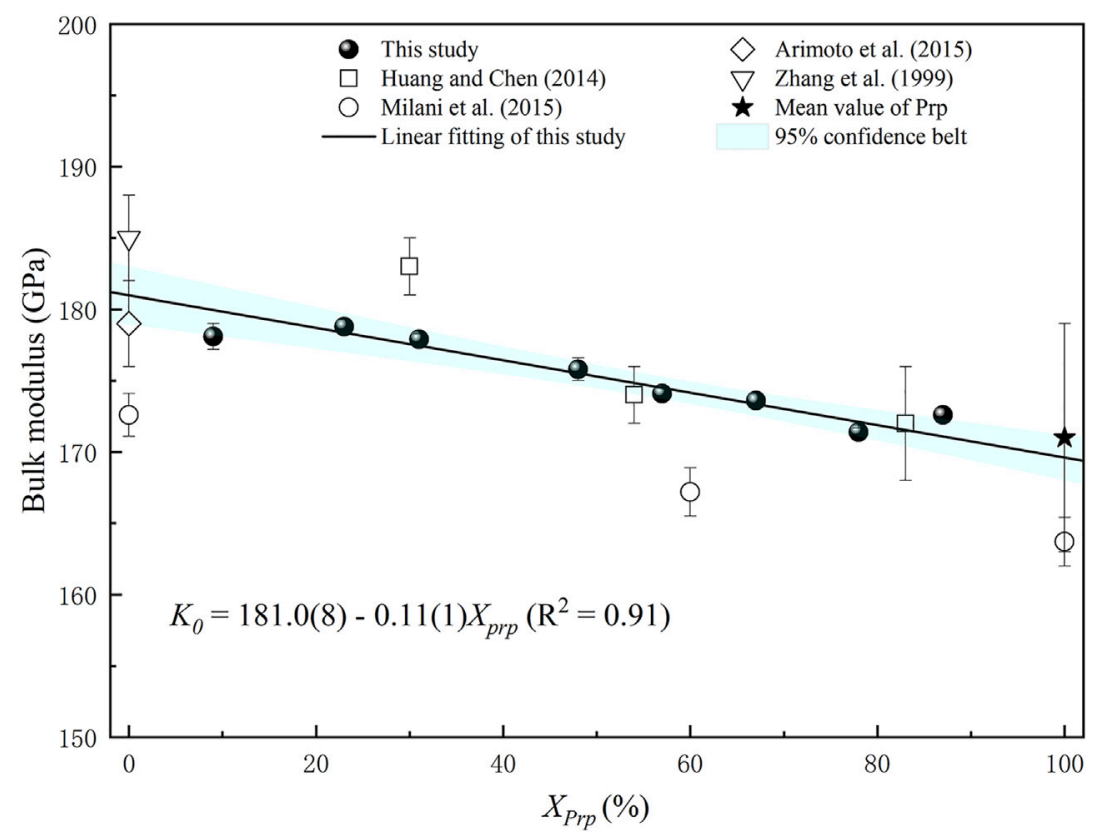

FIGURE 3 | Bulk moduli of pyrope-almandine solid solution garnets as a function of pyrope content.

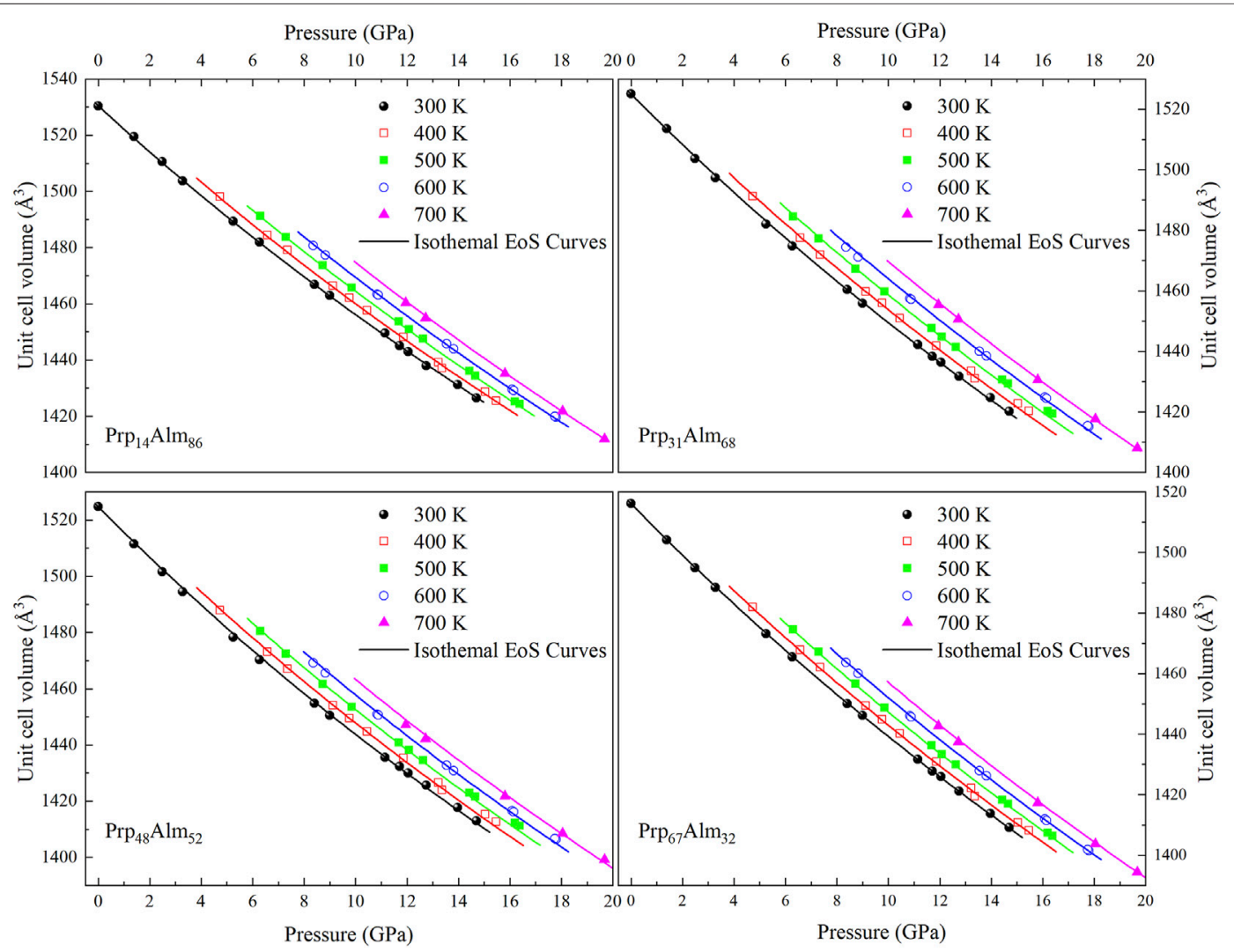

FIGURE 4 | The unit-cell volume of pyrope-almandine solid solution garnet as a function of pressure and temperature. The lines represent the isothermal compression curve from fitting HTBM EoS at 300, 400, 500, 600, and $700 \mathrm{~K}$. The error bars of the data points are smaller than the symbols. 
TABLE 2 | Thermoelastic parameters of garnets along the Prp-Alm join, as compared with previous studies.

\begin{tabular}{|c|c|c|c|c|c|c|c|}
\hline Composition & $V_{0}\left(\AA^{3}\right)$ & $K_{0}(\mathrm{GPa})$ & $K_{0}^{\prime}$ & $\alpha_{300}\left(10^{-5} \mathrm{~K}^{-1}\right)$ & $\theta_{\mathrm{E}}(\mathbf{K})$ & $\partial K / \partial T\left(\mathrm{GPaK}^{-1}\right)$ & References \\
\hline \multirow[t]{2}{*}{$\operatorname{Prp}_{14} \operatorname{Alm}_{86}$} & $1,530.5(1)$ & $184.7(9)$ & $3.6(1)$ & $2.95(5)$ & 560.8 & - & This study \\
\hline & $1,530.69(9)$ & $181.9(4)$ & $4^{a}$ & $3.00(5)$ & 560.8 & - & - \\
\hline \multirow[t]{2}{*}{$\operatorname{Prp}_{31} A_{1 m} 68$} & $1,525.05(2)$ & $171.6(6)$ & $5.4(1)$ & $3.59(4)$ & 507.2 & - & - \\
\hline & $1,525.02(5)$ & $179.1(4)$ & $4^{a}$ & $3.45(8)$ & 507.2 & - & - \\
\hline \multirow[t]{2}{*}{$\operatorname{Prp}_{48} \mathrm{Alm}_{52}$} & $1,524.5(3)$ & $158(1)$ & $5.6(2)$ & $3.63(5)$ & 465.6 & - & - \\
\hline & $1,522.5(2)$ & $169.9(6)$ & $4^{a}$ & 3.37 (6) & 465.6 & - & - \\
\hline \multirow[t]{2}{*}{$\operatorname{Prp}_{67} \mathrm{Alm}_{32}$} & $1,516.1(2)$ & $172(1)$ & $4.2(1)$ & $3.30(4)$ & 406.4 & - & - \\
\hline & $1,515.9(1)$ & $173.8(4)$ & $4^{a}$ & 3.27 (4) & 406.4 & - & - \\
\hline $\operatorname{Prp}_{100}$ & $1,504.64(4)$ & - & - & $2.543(5)$ & - & - & Milani et al. (2015) \\
\hline $\operatorname{Prp}_{100}$ & $1,503.1(5)$ & $170(2)$ & $5^{a}$ & $2.58(28)$ & - & $-0.020(3)$ & Wang et al. (1998) \\
\hline $\operatorname{Prp}_{100}$ & $1,500(2)$ & $167(3)$ & $4.6^{\mathrm{a}}$ & $2.89(33)$ & - & $-0.021(9)$ & Zou et al. (2012) \\
\hline Alm $_{100}$ & $1,531.05(7)$ & 179 (3) & $4^{a}$ & $3.3(9)$ & - & $-0.043(14)$ & Arimoto et al. (2015) \\
\hline $\mathrm{Alm}_{86} \operatorname{Prp}_{7} \mathrm{Spe}_{7}$ & 1,539.6 (9) & $177(2)$ & $4^{a}$ & $3.1(7)$ & - & $-0.032(16)$ & Fan et al. (2009) \\
\hline
\end{tabular}

higher $K_{0}^{\prime}$ [5.6 (5)-6.4 (4)] of Milani et al. (2015) than those of others [3.9 (3)-4.61 (14)] (Supplementary Table S2).

\section{Equations of State of Prp-Alm Solid Solutions at High Pressure and High Temperature}

The unit-cell volumes of $\operatorname{Prp}_{14} \mathrm{Alm}_{86}, \operatorname{Prp}_{31} \mathrm{Alm}_{68}, \operatorname{Prp}_{48} \mathrm{Alm}_{52}$, and $\operatorname{Prp}_{67} \mathrm{Alm}_{32}$ at $H P-H T$ conditions up to $\sim 19.67 \mathrm{GPa}$ and $700 \mathrm{~K}$ are shown in Supplementary Table S3. Figure 4 also shows the pressure-volume-temperature $(P-V-T)$ data of these Prp-Alm solid solution samples. In this study, we applied the thermal-pressure model EoS to describe the $P-V-T$ behavior of Prp-Alm solid solutions. There are two ways to calculate the $P-V-T$ properties of a mineral (as shown in Figure $\mathbf{1}$ of Milani et al., 2017). One way to characterize the $P-V-T$ behavior of minerals is to describe how the $V_{T O}, K_{T O}$, and $K_{T O}^{\prime}$ vary with temperature (at room pressure) and then use these parameters to calculate the isothermal compressibility at the high temperature (as shown by the rough path in Figure 1 of Milani et al., 2017). A potential weakness of this method is that the variation of $K_{T O}^{\prime}$ with temperature has rarely been measured, where $K_{T O}^{\prime}$ should increase slightly with increasing temperature, rather than not change with temperature, as the common assumption. Additionally, this assumption, coupled with the approximation that $\mathrm{d} K_{T O} / \mathrm{d} T$ is a constant, has often given rise to a non-physical negative coefficient of thermal expansion for many materials at reasonably moderate pressures (Helffrich and Connolly, 2009).

Furthermore, the maximum experimental temperature of only $700 \mathrm{~K}$ in this study and the relatively limited number of hightemperature data points make the fitting of the thermal expansion coefficient at high temperatures more inaccurate. Therefore, we employ the concept of thermal pressure (Anderson, 1995) to describe the $P-V-T$ behavior of Prp-Alm solid solutions. Then, as shown by the thin path in Figure $\mathbf{1}$ of Milani et al., 2017, the $P$ at a given $V$ and $T$ can be expressed as the sum of two terms:

$$
P(V, T)=P\left(V, T_{r e f}\right)+P_{t h}(T),
$$

The $P\left(V, T_{\text {ref }}\right)$ is the isothermal EoS for minerals at the reference temperature, up to the volume at $P$ and $T_{\text {ref. }}$ The

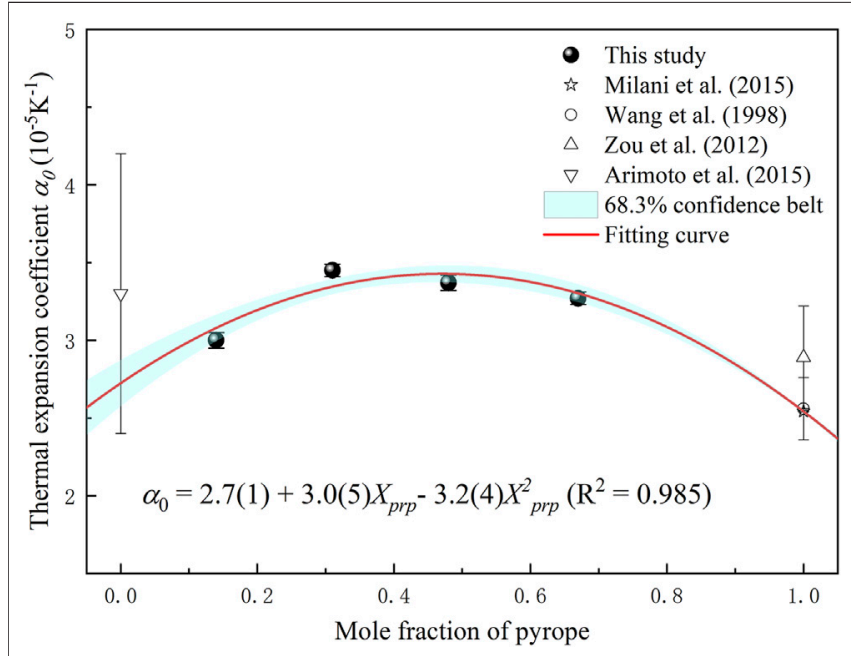

FIGURE 5| The thermal expansion coefficient of pyrope-almandine solid solution garnet at $300 \mathrm{~K}$ as a function of pyrope content.

thermal-pressure $\operatorname{Pth}(T)$ is the pressure generated by raising the temperature from $T_{\text {ref }}$ to $T$ at a constant volume, which is the isochor of the mineral passing through the final $P-T$ point. Details of the employment of a thermal-pressure EoS and any necessity assumptions have been reviewed by Milani et al. (2017). In this study, we used the Birch-Murnaghan isothermal EoS in combination with the Holland and Powell (2011) model of thermal-pressure EoS to determine the thermoelastic parameters of four Prp-Alm solid solutions, as shown in Table 2. All described in this study have been performed with the EosFit7c program (Angel et al., 2014a; Gonzalez-Platas et al., 2016). The Einstein temperature, $\theta_{E}$, of Prp-Alm solid solutions in this study are calculated from the values of the pyrope $(320 \mathrm{~K})$ and almandine $(400 \mathrm{~K})$ and according to the ideal solution model (Milani et al., 2015). The $V_{0}$ and $K_{T O}$ derived from $H P-H T$ data were roughly consistent with that from $P-V$ data at room temperature, especially as the $K_{T O}^{\prime}$ was fixed at 4 (Table 1 and Table 2).

Figure 5 shows the thermal expansion coefficient at ambient conditions $\left(\alpha_{0}\right)$ of four Prp-Alm solid solutions in this study, combined with the results from previous studies. As shown in 
Figure 5, there is a non-linear correlation between $\alpha_{0}$ and the Prp content of the Prp-Alm solid solution. The $\alpha_{0}$ of Prp-Alm solid solution varies with the composition getting a parabola. At ambient conditions, Prp-Alm solid solution with intermediate composition demonstrates a larger $\alpha_{0}$ than the composition close to endmember, the maximum variation in the $\alpha_{0}$ from $\operatorname{Prp}_{14} \mathrm{Alm}_{86}$ to $\operatorname{Prp}_{48} \mathrm{Alm}_{52}$ is about $23 \%$. The $\alpha_{0}$ of the PrpAlm solid solutions as a function of Prp content can be expressed by $\alpha_{0}\left(10^{-5} \mathrm{~K}^{-1}\right)=2.7(1)+3.0(5) X_{\operatorname{Prp}}-3.2(4) X_{\operatorname{Prp}}^{2}\left(R^{2}=0.985\right)$.

\section{DISCUSSION}

\section{$\mathrm{Mg}^{2+}-\mathrm{Fe}^{2+}$ Substitution Effect on Bulk Moduli of Prp-Alm Solid Solutions}

Among previous studies about the compositional effect on bulk modulus of different mineral groups, minerals with $\mathrm{Mg}^{2+}-\mathrm{Fe}^{2+}$ solid solutions have been extensively investigated because of their importance in understanding the composition and dynamic property of the Earth's interior (Takahashi and Liu, 1970; Zhang J. et al., 1998; Zhang et al., 1999; Speziale et al., 2004; Huang and Chen, 2014). The Fe and Mg component dependence of bulk modulus in mantle minerals is interesting for modeling the mineralogical composition of the mantle and mineral crystal chemistry. Anderson and Anderson (1970) proposed a simple bulk modulus $\left(K_{0}\right)$-volume $\left(V_{0}\right)$ systematics, where $K_{0} V_{0}=$ constant. However, for most of the ferromagnesian silicates and carbonates that have been studied so far, the bulk modulus appears to increase with increasing Fe content, such as garnet (Huang and Chen, 2014), olivine (Speziale et al., 2004), and siderite (Zhang J. et al., 1998), which is inconsistent with bulk modulus-volume systematics. To sum up, it is necessary to understand the $\mathrm{Mg}^{2+}-\mathrm{Fe}^{2+}$ substitution effect on the bulk modulus of garnet.

Figure 3 shows the bulk moduli of Prp-Alm solid solutions as functions of compositions in this study and compared with those of previous studies. $\mathrm{Mg}^{2+}-\mathrm{Fe}^{2+}$ substitution results in a nearly linear decrease of the bulk modulus. The reduction of bulk moduli from $\operatorname{Prp}_{9} \mathrm{Alm}_{91}$ to $\operatorname{Prp}_{87} \mathrm{Alm}_{12}$ is $\sim 3 \%$, mainly consistent with the $\sim 6 \%$ decrease from $\operatorname{Prp}_{30} \mathrm{Alm}_{70}$ to $\operatorname{Prp}_{83} \mathrm{Alm}_{17}$ reported by Huang and Chen (2014).

The bulk moduli of minerals are mainly controlled by their constituent polyhedral compressibilities, primarily determined by the mean cation-oxygen bond length in the polyhedral (Hazen et al., 1994). Many previous high-pressure studies have shown that the $\mathrm{SiO}_{4}$ tetrahedrons of silicate minerals are essentially rigid units (Robinson et al., 1971; Zhang et al., 1997; Xu et al., 2017). The selected bond distances of Prp-Alm solid solutions at the ambient condition (data from Kuang et al., 2019) as functions of composition are shown in Figure 6. Inspection of Figure 6 demonstrates that the $d_{<\mathrm{M}-\mathrm{O}>}(\mathrm{M}$ is the divalent cations in $\mathrm{X}$-site) decreases significantly with the increasing Prp content, mainly due to the smaller effective ionic radius of $\mathrm{Mg}^{2+}(0.89 \AA)$ in eightfold coordination than that of $\mathrm{Fe}^{2+}(0.92 \AA)$ (Shannon, 1976). In contrast, the average $d_{<\mathrm{Si}-\mathrm{O}>}$ of the $\mathrm{SiO}_{4}$ tetrahedron and $d_{<\mathrm{Al}-\mathrm{O}>}$ of the $\mathrm{AlO}_{6}$ octahedron change negligibly with increasing Prp mol\%. These results imply that the compressibility of the
$\mathrm{MO}_{8}$ dodecahedron mainly controls the bulk modulus of the PrpAlm solid solution. However, other factors, such as the compressibilities of the $\mathrm{SiO}_{4}$ tetrahedron and the $\mathrm{AlO}_{6}$ octahedron, may be secondary important to the bulk modulus of Prp-Alm solid solution.

Besides, this study shows that $\mathrm{FeO}_{8}$ dodecahedron is less compressible than $\mathrm{MgO}_{8}$ dodecahedron. Similar conclusions were also obtained about the structures with sixfold coordinated $\mathrm{Mg}^{2+}$ and $\mathrm{Fe}^{2+}$ cations (Zhang et al., 1997), implying that the bonding character plays an essential role in such anomalous compression, whereas structure type and polyhedral coordination may be less critical. Furthermore, the electronegativity of the element, which describes the ability of an atom to attract electrons, may be an essential factor for the bonding character. The electronegativity of $\mathrm{Mg}$ (1.31) is distinctly smaller than that of $\mathrm{Fe}$ (1.83) (Allred, 1961), resulting in the less compressible $\mathrm{FeO}_{8}$ dodecahedron than $\mathrm{MgO}_{8}$ dodecahedron.

Moreover, Hazen et al. (1994) suggested that the $\mathrm{SiO}_{4}$ octahedra and $\mathrm{AlO}_{6}$ tetrahedra framework may also dictate the bulk modulus of garnet. Subsequently, Zhang L. et al. (1998) showed that the kinking degree of the $\mathrm{Si}-\mathrm{O}-\mathrm{Al}$ angle decreased continuously with increasing pressure, and the $\mathrm{Si}-\mathrm{O}-\mathrm{Al}$ angle in Alm is less kinked than that in Prp over the same pressure range (Zhang et al., 1999). Furthermore, the Raman spectroscopy results of Kuang et al. (2019) show that both the stretching motions of $\mathrm{Si}-\mathrm{O}$ and the rotation motions of $\mathrm{SiO}_{4}$ decreased linearly with increasing Alm content. Thus, the degree of distortion and rotation of $\mathrm{SiO}_{4}$ may also affect the bulk moduli of the Prp-Alm solid solutions.

To sum up, the bulk moduli of Prp-Alm solid solutions are primarily governed by the compressibility of $\mathrm{MO}_{8}$ dodecahedra. The difference in the compressibilities of $\mathrm{MO}_{8}$ can be attributed to the different effective ionic radius and electronegativities of the $\mathrm{Mg}$ and $\mathrm{Fe}$ atoms. Also, the kinking degree of the Si-O-Al angle and the distortion and rotation of $\mathrm{SiO}_{4}$ may affect the bulk moduli of Prp-Alm solid solutions.

\section{$\mathrm{Mg}^{2+}-\mathrm{Fe}^{2+}$ Substitution Effect on Thermal Expansion Coefficient of Prp-Alm Solid Solutions}

Contrary to the effect of $\mathrm{Mg}^{2+}-\mathrm{Fe}^{2+}$ substitution on the bulk modulus of Prp-Alm solid solutions, the $\alpha_{0}$ of Prp-Alm solid solutions varies with the composition forming a parabola. As shown in Figure 5, at ambient temperatures, the composition of the Prp-Alm solid solution near the intermediate composition displays a larger thermal expansion coefficient than the composition near the endmember. While the causes of this result are yet to be revealed, we think that the most likely reason is the local arrangement of $\mathrm{Mg}^{2+}$ and $\mathrm{Fe}^{2+}$. For the garnet, the different-sized divalent cations substitution on the dodecahedral site can make its thermodynamic properties (e.g., volume, enthalpy, entropy, free energy, etc.) deviate from the ideal mixing results (Bosenick et al., 2001; Vinograd et al., 2004; Dachs et al., 2014; Du et al., 2016). Besides, the magnitude of the non-ideal mixing is correlated with the size difference between 


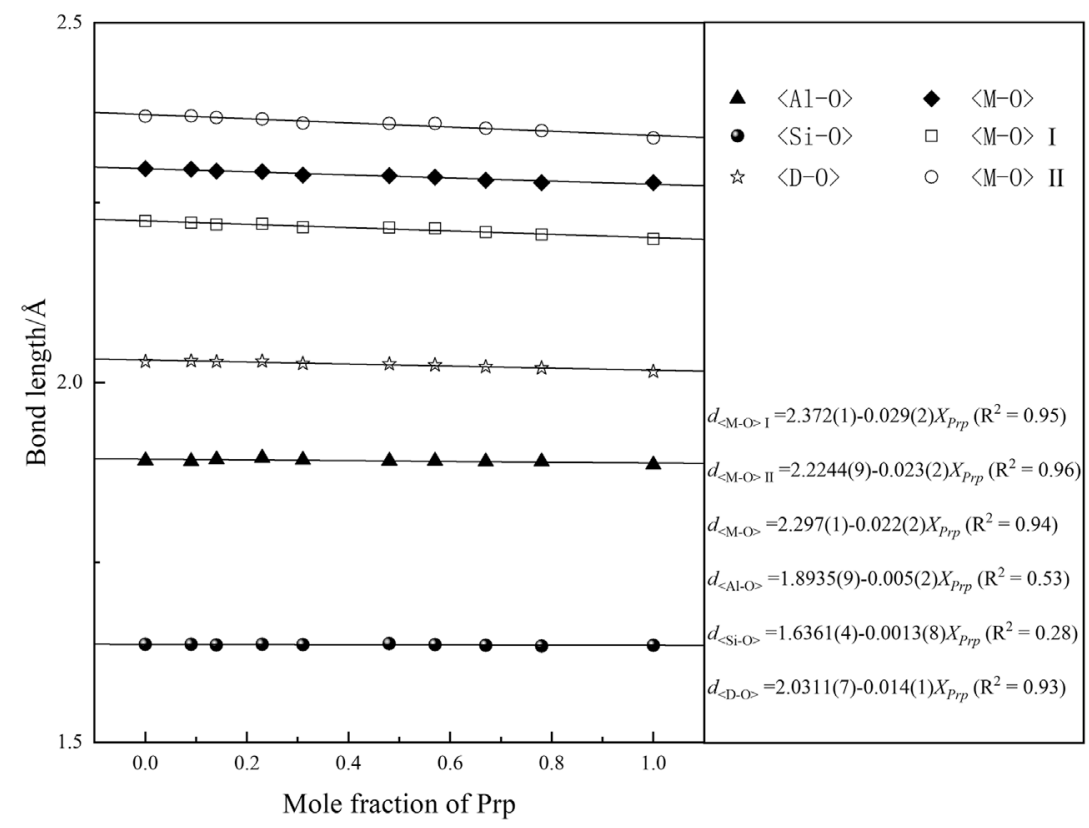

FIGURE 6 | The bond length of the pyrope-almandine solid solution garnet at ambient conditions as a function of pyrope content.

the substituting cations on the dodecahedral site (Geiger and Rossman, 1994). The study on the local structure of the pyropegrossular garnet solid solution shows that the $\mathrm{Mg} / \mathrm{Ca}$ substitution can produce significant amounts of short-range order rather than long-range order in garnets (Bosenick et al., 2000). Furthermore, the compositions near $\operatorname{Prp}_{50} \mathrm{Grs}_{50}$ depart most strongly from random mixing, and all the compositions tend to random disorder at high temperatures. Although the size difference between $\mathrm{Mg}^{2+}(0.89 \AA)$ and $\mathrm{Fe}^{2+}(0.92 \AA)$ is smaller than that between $\mathrm{Mg}^{2+}$ and $\mathrm{Ca}^{2+}$ (1.12 $\AA$ ) (Shannon, 1976), the influence on the local arrangement by the $\mathrm{Mg} / \mathrm{Fe}$ substitution cannot be overlooked. It is speculated that local disorder caused by the $\mathrm{Mg} /$ Fe substitution is the main reason for a non-linear relationship between thermal expansion coefficient and the composition of the Prp-Alm solid solution.

\section{IMPLICATIONS FOR ELASTIC GEOBAROMETER}

It is ordinary to use host-inclusion systems to infer the geological history of a mineral or a rock (Guiraud and Powell, 2006). The history of study on elastic geobarometers can be traced back to the 1980s. Roedder and Bodnar (1980) made the first estimation for the formation pressure of minerals from the fluid inclusions in them. The basic principle is that when the host mineral captures the fluid, it experiences a different $P-T$ path than the host mineral because its volume is limited by the space inside the mineral and is subjected to the pressure exerted on it by the host mineral during subsequent changes in temperature and pressure conditions. In turn, this difference and its associated physicochemical properties can be used to estimate the $P-T$ conditions experienced by the host mineral. This principle is not only applicable to fluid/melt inclusions but also to other solid mineral inclusions within the mineral that differ from its thermoelastic properties. This method underwent significant developments in the past decade and is gradually gaining the interest of geologists (e.g., Murri et al., 2018; Alvaro et al., 2019; Anzolini et al., 2019; Bonazzi et al., 2019; Gonzalez et al., 2019; Mazzucchelli et al., 2019; Moulas et al., 2020).

The pressure estimation by an elastic geobarometer has some prerequisite assumptions (Bonazzi et al., 2019): (1) The inclusions are in the same pressure environment as the host mineral at the time of capture, and the inclusions fill the vacancies entirely within the host mineral. (2) The host mineral and the inclusions are always reversibly and elastically deformed after capture. In this way, the captured pressure can be estimated by measuring the residual pressure of the inclusions due to the difference in elastic properties between the two minerals under normal temperature and pressure conditions and by combining the equation of the state of the two minerals. In this study, the method for estimating the pressure is based on entrapment isomekes proposed by Angel et al. (2017b). Entrapment isomekes is a single $P-T$ path along which the fractional volume change in host and inclusion are equal (Gonzalez et al., 2019). The calculation of $P_{e}$ was performed with EosFit-Pinc, and the details of this method were described in Angel et al. (2017b).

As mentioned in the introduction section of this study, much of the previous work has focused on the factors affecting the calculation accuracy of the elastic geobarometer except the influence of the thermoelastic parameters of minerals. So, we selected two garnet-related host-inclusion pairs to evaluate the influence of the thermoelastic parameters of the concerned minerals on the calculated results of elastic geobarometers. 
TABLE 3 | Room pressure-temperature EoS coefficients for selected minerals ( Prp-Alm garnets, diamond and quartz).

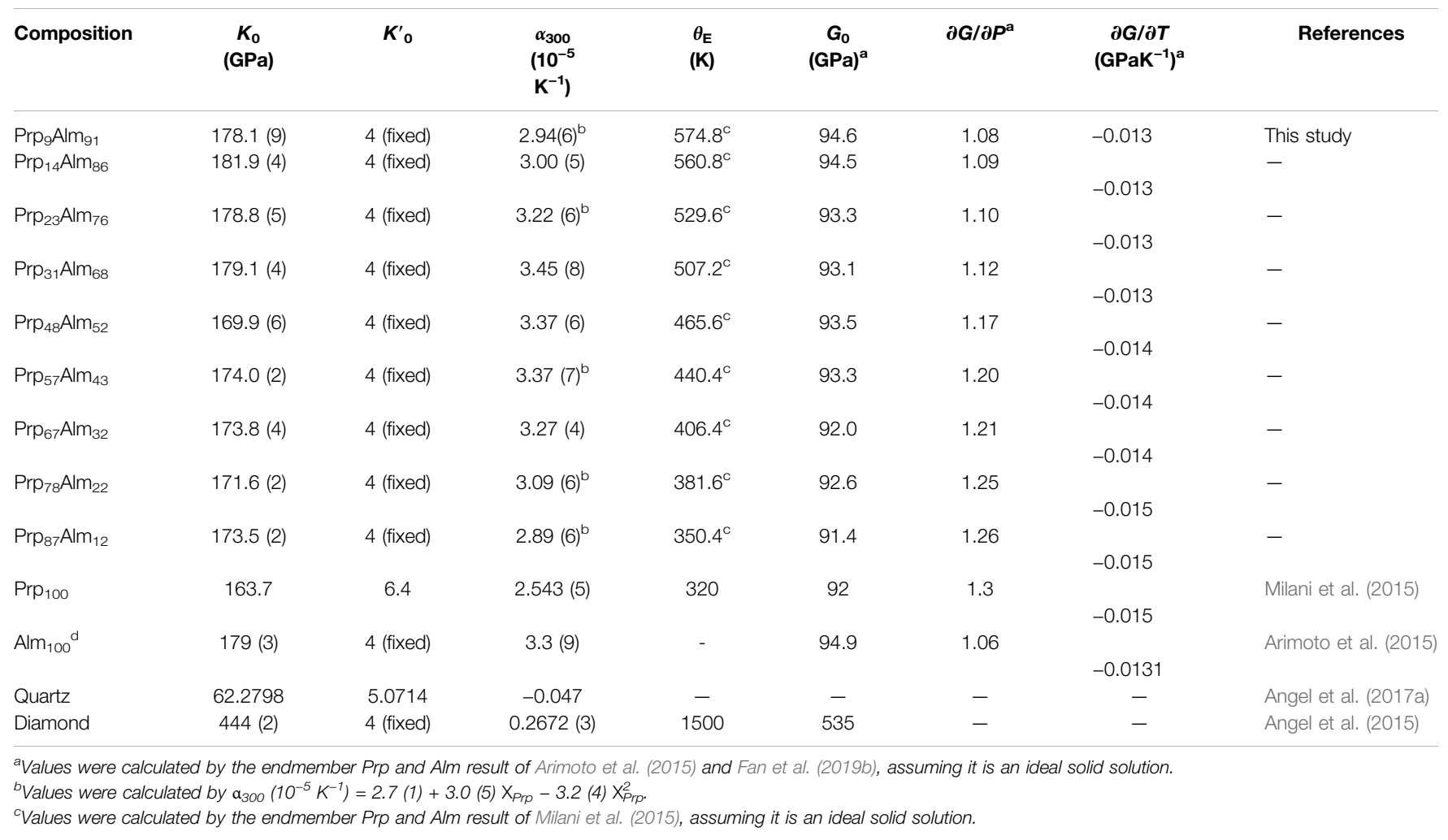

Quartz is generally a virtually pure endmember, and it is stable over a wide range of metamorphic conditions (Korsakov et al., 2009). Garnet has also served as a central focus of metamorphic studies to discern $P-T$ paths because it can store the entire history of metamorphism by its inclusion suites such as quartz, graphite, and rutile (Ague and Carlson, 2013; Baxter et al., 2013; Caddick and Kohn, 2013). Hence, QuiG is considered a particularly useful geobarometer and has been widely used to infer the geological history of the rock from the collisional orogenic belts (Wolfe and Spear, 2018), the subduction complex (Bayet et al., 2018; Alvaro et al., 2019), and ultrahigh-pressure metamorphic complex (Korsakov et al., 2009; Gonzalez et al., 2019; Zhong et al., 2019; Moulas et al., 2020). Similarly, as the primeval samples from inaccessible regions of Earth, diamonds and their inclusions provide direct information of deep Earth's evolution. This information is precious if it can be combined with depth estimates (Anzolini et al., 2019). An estimate of their formative pressure (depth of provenance) can be used to constrain and understand the environment in which they formed. Therefore, the thermoelastic parameters of the minerals play a crucial role in determining the accuracy of the pressure calculation. The garnet, a widespread mineral solid solution in nature, can have varying elastic properties depending on its composition (Du et al., 2015; Fan et al., 2017; Fan et al., 2018; Xu et al., 2019). In most cases, however, the thermoelastic properties used for calculation are the results of the endmember garnet (Milani et al., 2015; Gonzalez et al., 2019; Zhong et al., 2019), or assumed that the solid solution is isotropic and ideal (Johnson et al., 2021). Based on the results of this study, the thermoelastic properties of the Prp-Alm solid solutions may not follow the ideal mode (e.g., Figure 5). Therefore, the thermoelastic properties of garnet estimated from the endmember components may cause divergence. It is necessary to discuss the influence of garnet composition on the accuracy of these two elastic geobarometers.

These calculations utilized the thermoelastic coefficients of quartz with a curved $\alpha-\beta$ transition (Angel et al., 2017a) and the thermoelastic coefficients of the diamond from Angel et al. (2015). The shear modulus and its $P$ and $T$ derivative of PrpAlm garnet were calculated by combining the results of the endmembers pyrope and almandine in proportion to their measured abundances, assumed as an ideal solid solution (Arimoto et al., 2015; Fan et al., 2019b). The final full set of thermoelastic coefficients for the $P_{e}$ estimation are shown in Table 3.

Firstly, the uncertainties of the thermoelastic properties of garnets in the QuiG application should be considered. Here, we take the $\operatorname{Prp}_{14} \mathrm{Alm}_{86}$ garnet to demonstrate the effect of the uncertainties in thermoelastic properties. We chose $0.65 \mathrm{GPa}$ as the $P_{i n c}$ obtained by laser Raman spectroscopy for quartz inclusions in garnet from eclogite for our $P_{e}$ estimation (Zhong et al., 2019). Supplementary Table S4 lists the calculated $P_{e}$ for $\operatorname{Prp}_{14} \mathrm{Alm}_{86}$ considering the uncertainties of the thermoelastic properties. Compared to the bulk modulus, the thermal expansion coefficient in this study has the most considerable effect in calculated $P_{e}$ (Figure 7A). A $1.7 \%$ uncertainty in the value of $\alpha_{0}$ of garnet 

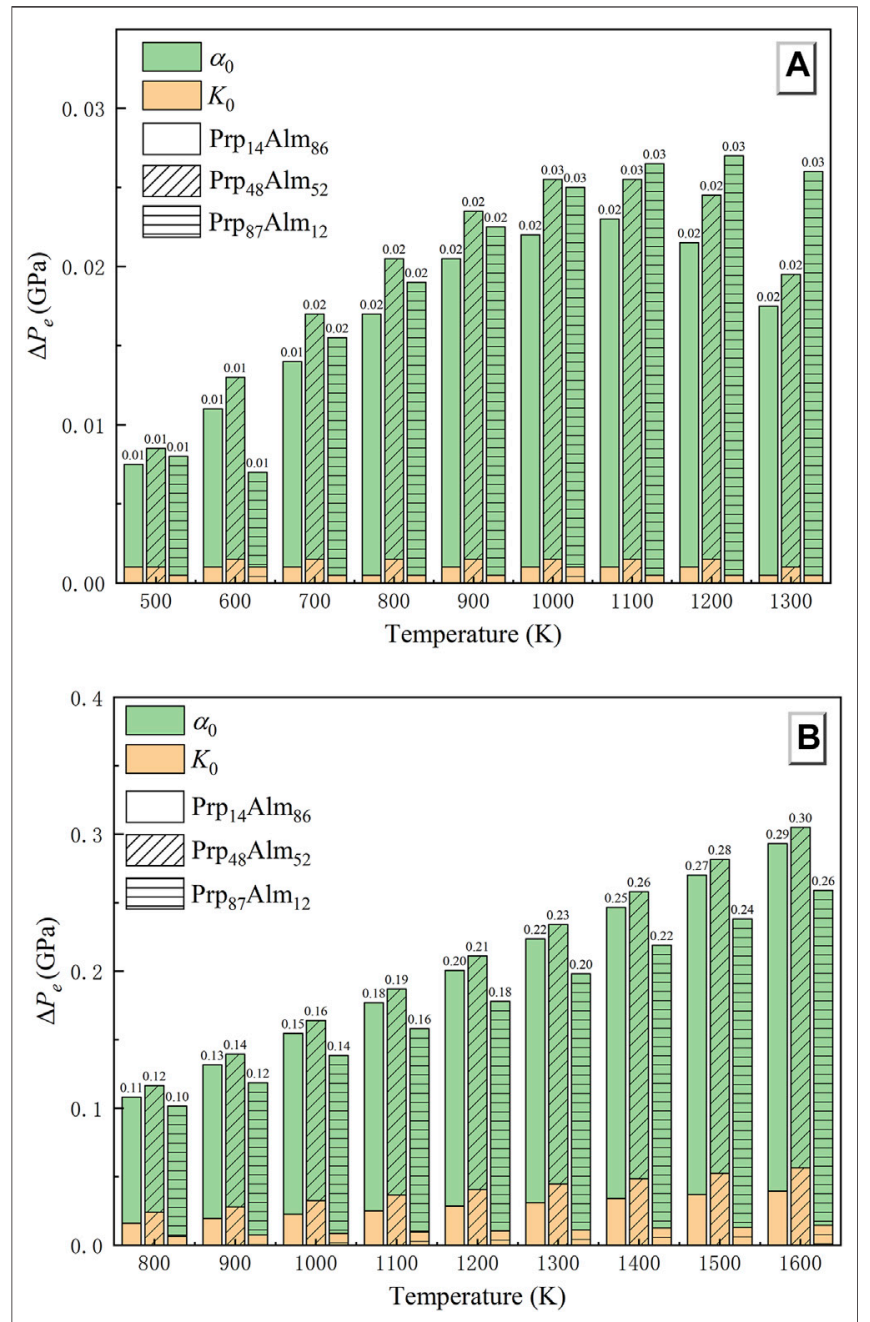

FIGURE 7 | The total uncertainty of the thermal equation of state parameters on the results of $P_{e}$. (A): Garnet-quartz elastic barometer; (B): Diamond-garnet elastic barometer.

changes the $P_{e}$ by $\sim 0.007 \mathrm{GPa}$ at $500 \mathrm{~K}$, and with the temperature rising, it makes the $P_{e}$ change $\sim 0.016 \mathrm{GPa}$ at $1300 \mathrm{~K}$. The accuracy of bulk modulus obtained in this study has almost no effect on the $P_{e}$ estimation. A $0.22 \%$ uncertainty in the value of $K_{0}$ of garnet changes the $P_{e}$ by only $0.001 \mathrm{GPa}$. In conclusion, the maximal error caused by the thermoelastic properties of garnet on $P_{e}$ estimation is less than $0.02 \mathrm{GPa}$ (Figure 7A). Besides, as shown in Figure 7A, we have calculated the $P_{e}$ of the other two garnets with different components $\left(\operatorname{Prp}_{48} \mathrm{Alm}_{52}\right.$ and $\left.\operatorname{Prp}_{87} \mathrm{Alm}_{12}\right)$, and the results obtained are consistent with the $\operatorname{Prp}_{14} \mathrm{Alm}_{86}$.

For the $P_{e}$ calculations of the diamond-garnet pair, we assume a residual pressure $P_{\text {inc }}$ on the garnet inclusion of 0.2 (1) GPa, and we use the thermoelastic properties given in Table 3. Supplementary Table S5 lists the calculated $P_{e}$ for $\operatorname{Prp}_{14} \mathrm{Alm}_{86}$. The conclusions drawn from Supplementary Table S5 and Figure 7B are that a $0.22 \%$ uncertainty of $K_{0}$ may contribute an error of $\sim 0.03 \mathrm{GPa}$ to the calculated $P_{e}$. Same as in QuiG, the thermal expansion coefficient in this study has the most considerable effect in the calculated $P_{e}$ of
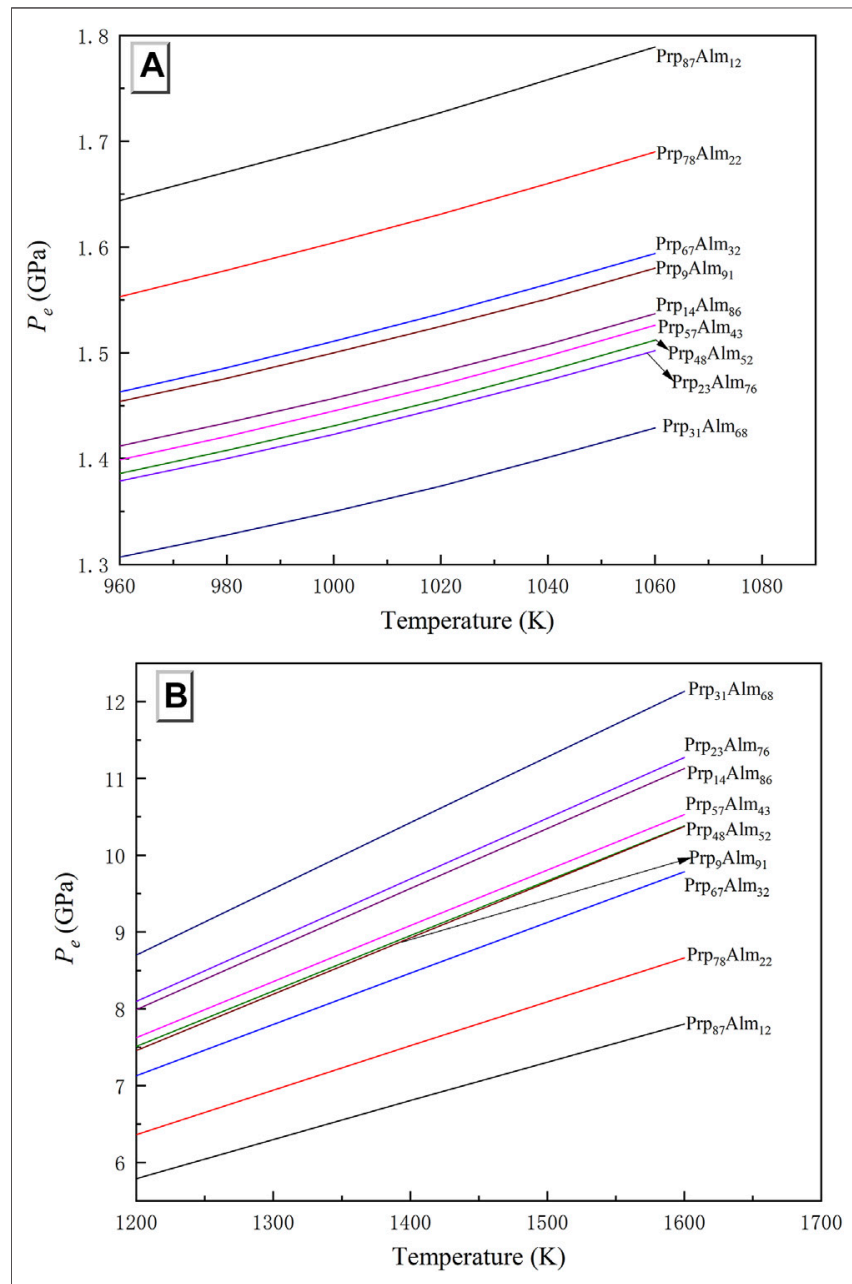

FIGURE $8 \mid P_{e}$ results for different garnet components in (A) Garnetquartz elastic barometer and (B) Diamond-garnet elastic barometer.

the diamond-garnet system (Figure 7B). A 1.7\% uncertainty in the value of $\alpha_{0}$ of garnet changes the $P_{e}$ by $\sim 0.092 \mathrm{GPa}$ at $800 \mathrm{~K}$, and with the temperature rising, it makes the $P_{e}$ change $\sim 0.254 \mathrm{GPa}$ at $1600 \mathrm{~K}$. The maximal error caused by the thermoelastic properties of garnet in the diamond-garnet system is $\sim 0.3 \mathrm{GPa}$ at $1,600 \mathrm{~K}$ (Figure 7B). It can be found that for the same garnet composition, the $P_{e}$ change caused by the uncertainties of its thermoelastic properties is unequal in the two types of elastic geobarometers. The $P_{e}$ change in the diamond-garnet pair is almost ten times as large as it is in QuiG.

Here, the Pyp-Alm garnets of different compositions (Table 3) are used to calculate the $P_{e}$, and the results of two elastic geobarometers are shown in Figures $\mathbf{8 A}, \mathbf{B}$. The effect of garnet composition on the predicted entrapment pressure is relatively large, especially for the diamond-garnet system (Figure 8B). At $1,400 \mathrm{~K}$, the different compositions of garnet can cause a variation of $P_{e}$ up to $4.5 \mathrm{GPa}$ in the diamond-garnet system. In the QuiG, the difference of inferred entrapment pressure may reach ca. $0.35 \mathrm{GPa}$ at $1,060 \mathrm{~K}$. As mentioned 
above, this is mainly due to the distinct thermal expansion coefficient among them.

To sum up, even though the procedure of applying an elastic barometer to host-inclusion mineral systems requires several steps that involve various assumptions (Angel et al., 2015), and there are lots of possible factors that could influence the precision and accuracy of calculated $P_{e}$ value as mentioned above, its advantages could not be ignored. Much previous work suggested that QuiG, and diamond-garnet elastic barometer, may preserve different aspects of garnet history in complex terranes (Wolfe and Spear, 2018; Alvaro et al., 2019; Spear and Wolfe, 2020; Johnson et al., 2021). The advantages of QuiG or other inclusion-based methods are relatively easy to apply and require far less data acquisition than conventional methods. Our results suggest that the entrapment pressure may be significantly influenced by the thermoelastic parameters of garnet, which is selected to have a different component from the research sample, while the thermal expansion coefficient is the main influencing factor for the elastic barometer to $P_{e}$ estimation, compared with other thermoelastic parameters. Therefore, the effect of the composition of garnet on the $P_{e}$ estimation could not be ignored. Furthermore, one factor that must not be overlooked is the effect of viscous relaxation, which occurs very rapidly at temperatures $>110 \mathrm{~K}$ (Moulas et al., 2020) and the preserved $P_{e}$ may then be a reflection of re-equilibration (Zhong et al., 2020). In the future application of elastic barometer, as the most common garnet component in the Earth, the thermoelastic parameters (especially the thermal expansion coefficient) of the pyrope-almandine-grossular ternary solid solutions must also be considered.

\section{CONCLUSION}

In summary, the thermoelastic parameters of systematic Prp-Alm solid solutions were obtained by fitting the $P-V-T$ or $P-V$ data to the EoS and compared with previous studies. The relationship between the bulk moduli of the Prp-Alm solid solutions and Prp content can be expressed as $K_{0}(\mathrm{GPa})=181.0(8)-0.11(1) X_{\text {prp }}\left(R^{2}=0.91, K_{0}^{\prime}\right.$ fixed at 4). Our results demonstrate that the Prp content will decrease the incompressibilities of Prp-Alm solid solutions, which is inconsistent with bulk modulus-volume systematics: $K_{0} V_{0}=$ constant. The possible reasons for this difference may be multiple and complicated. In our view, the most likely reason is the larger compressibility of $\mathrm{MgO}_{8}$ than that of $\mathrm{FeO}_{8}$. Also, the kinking degree of the $\mathrm{Si}-\mathrm{O}-\mathrm{Al}$ angle and the degree of distortion and rotation of $\mathrm{SiO}_{4}$ may affect the compressibilities of the Prp-Alm solid solutions. The thermal expansion coefficient with the component of Prp-Alm solid solution also has a relational expression, $\alpha_{0}\left(10^{-5} \mathrm{~K}^{-1}\right)=2.7(1)+3.0$ (5) $X_{\text {Prp }}-3.2$ (4) $X_{\operatorname{Prp}}^{2}\left(R^{2}=0.985\right)$, where the Prp-Alm solid solutions with intermediate composition show a larger coefficient than the endmembers at ambient condition. Furthermore, for two types of elastic geobarometers, we evaluate the correlation of the uncertainties of thermoelastic properties with $P_{e}$ estimation accuracy. Compared with bulk modulus, the thermal expansion coefficient has the main effect on the estimation of $P_{e}$. The $P_{e}$ change caused by the uncertainties of thermoelastic properties of garnets in the diamond-garnet pair is almost 10 times larger than it is in QuiG. Besides, by calculating $P_{e}$ with different garnet components, the result suggests that the garnet component may significantly influence entrapment pressure, especially in the diamond-garnet system and the pyrope-almandine-grossular ternary solid solutions EoS must also be considered in the future study.

\section{DATA AVAILABILITY STATEMENT}

The original contributions presented in the study are included in the article/Supplementary Material, further inquiries can be directed to the corresponding author.

\section{AUTHOR CONTRIBUTIONS}

Conceptualization and methodology, DF and WZ; investigation, $\mathrm{BL}$, JX, ST, and VP; sample source, BL and WZ; experimental analysis, BL, JX, DF, and WZ; writing-original draft preparation, $\mathrm{BL}$; writing-review and editing, DF, WZ, JJ, JX, BL, ZY, SH, WG, and YZ; plotting, BL; software, BL and JX. All authors have read and agreed to the published version of the manuscript.

\section{FUNDING}

This project was supported by the National Natural Science Foundation of China (Grant Nos. 41802043, U2032118, and 42172048), the Youth Innovation Promotion Association CAS (DF, 2018434), the Chinese Academy of Sciences "Light of West China" Program (2019), the Science and Technology Foundation of Guizhou Province (QKHJC-ZK (2021) ZD042), and the Innovation and Entrepreneurship Funding of High-Level Overseas Talents of Guizhou Province (DF, (2019) 10).

\section{ACKNOWLEDGMENTS}

We acknowledge Wei Chen and Yunqian Kuang for the High $P-T$ experiments assistance. The experimental works were conducted at the GeoSoilEnviroCARS (Sector 13), Advanced Photon Source (APS), and Argonne National Laboratory.

\section{SUPPLEMENTARY MATERIAL}

The Supplementary Material for this article can be found online at: https://www.frontiersin.org/articles/10.3389/feart.2021.833405/ full\#supplementary-material 


\section{REFERENCES}

Ague, J. J., and Carlson, W. D. (2013). Metamorphism as Garnet Sees it: The Kinetics of Nucleation and Growth, Equilibration, and Diffusional Relaxation. Elements 9, 439-445. doi:10.2113/gselements.9.6.439

Allred, A. L. (1961). Electronegativity Values from Thermochemical Data. J. Inorg. Nucl. Chem. 17, 215-221. doi:10.1016/0022-1902(61)80142-5

Alvaro, M., Mazzucchelli, M. L., Angel, R. J., Murri, M., Campomenosi, N., Scambelluri, M., et al. (2019). Fossil Subduction Recorded by Quartz from the Coesite Stability Field. Geology 48, 24-28. doi:10.1130/g46617.1

Anderson, D. L., and Anderson, O. L. (1970). Brief Report: The Bulk ModulusVolume Relationship for Oxides. J. Geophys. Res. 75, 3494-3500. doi:10.1029/ JB075i017p03494

Anderson, O. L. (1995). Equations of State of Solids for Geophysics and Ceramic Science. New York: Oxford University Press on Demand.

Angel, R. J., Alvaro, M., and Gonzalez-Platas, J. (2014a). EosFit7c and a Fortran Module (Library) for Equation of State Calculations. Z. Kristallogr Cryst. Mater. 229, 405-419. doi:10.1515/zkri-2013-1711

Angel, R. J., Alvaro, M., Miletich, R., and Nestola, F. (2017a). A Simple and Generalised P-T-V EoS for Continuous Phase Transitions, Implemented in EosFit and Applied to Quartz. Contrib. Mineral. Petrol. 172, 29. doi:10.1007/ s00410-017-1349-x

Angel, R. J., Alvaro, M., Nestola, F., and Mazzucchelli, M. L. (2015). Diamond Thermoelastic Properties and Implications for Determining the Pressure of Formation of Diamond-Inclusion Systems. Russ. Geol. Geophys. 56, 211-220. doi:10.1016/j.rgg.2015.01.014

Angel, R. J. (2000). Equations of State. Rev. Mineralogy Geochem. 41, 35-59. doi:10. 2138/rmg.2000.41.2

Angel, R. J., Mazzucchelli, M. L., Alvaro, M., and Nestola, F. (2017b). EosFit-Pinc: A Simple GUI for Host-Inclusion Elastic Thermobarometry. Am. Mineral. 102, 1957-1960. doi:10.2138/am-2017-6190

Angel, R. J., Mazzucchelli, M. L., Alvaro, M., Nimis, P., and Nestola, F. (2014b). Geobarometry from Host-Inclusion Systems: The Role of Elastic Relaxation. Am. Mineral. 99, 2146-2149. doi:10.2138/am-2014-5047

Anzolini, C., Nestola, F., Mazzucchelli, M. L., Alvaro, M., Nimis, P., Gianese, A., et al. (2019). Depth of Diamond Formation Obtained from Single Periclase Inclusions. Geology 47, 219-222. doi:10.1130/g45605.1

Arimoto, T., Gréaux, S., Irifune, T., Zhou, C., and Higo, Y. (2015). Sound Velocities of Fe3Al2Si3O12 Almandine up to $19 \mathrm{GPa}$ and 1700 K. Phys. Earth Planet. Interiors 246, 1-8. doi:10.1016/j.pepi.2015.06.004

Ashley, K. T., Caddick, M. J., Steele-Macinnis, M. J., Bodnar, R. J., and Dragovic, B. (2014). Geothermobarometric History of Subduction Recorded by Quartz Inclusions in Garnet. Geochem. Geophys. Geosyst. 15, 350-360. doi:10.1002/ $2013 \mathrm{gc} 005106$

Ashley, K. T., Steele-Macinnis, M., Bodnar, R. J., and Darling, R. S. (2016). Quartzin-garnet Inclusion Barometry under Fire: Reducing Uncertainty from Model Estimates. Geology 44, 699-702. doi:10.1130/g38211.1

Bass, J. D., Sinogeikin, S. V., and Li, B. (2008). Elastic Properties of Minerals: A Key for Understanding the Composition and Temperature of Earth's Interior. Elements 4, 165-170. doi:10.2113/gselements.4.3.165

Baxter, E. F., Caddick, M. J., and Ague, J. J. (2013). Garnet: Common Mineral, Uncommonly Useful. Elements 9, 415-419. doi:10.2113/gselements.9.6.415

Bayet, L., John, T., Agard, P., Gao, J., and Li, J.-L. (2018). Massive Sediment Accretion at $\sim 80 \mathrm{Km}$ Depth along the Subduction Interface: Evidence from the Southern Chinese Tianshan. Geology 46, 495-498. doi:10.1130/g40201.1

Bebout, G. E. (2007). Metamorphic Chemical Geodynamics of Subduction Zones. Earth Planet. Sci. Lett. 260, 373-393. doi:10.1016/j.epsl.2007.05.050

Bonazzi, M., Tumiati, S., Thomas, J. B., Angel, R. J., and Alvaro, M. (2019). Assessment of the Reliability of Elastic Geobarometry with Quartz Inclusions. Lithos 350-351, 105201. doi:10.1016/j.lithos.2019.105201

Bosenick, A., Dove, M. T., and Geiger, C. A. (2000). Simulation Studies on the Pyrope-Grossular Garnet Solid Solution. Phys. Chem. Minerals 27, 398-418. doi:10.1007/s002690000088

Bosenick, A., Dove, M. T., Heine, V., and Geiger, C. A. (2001). Scaling of Thermodynamic Mixing Properties in Garnet Solid Solutions. Phys. Chem. Minerals 28, 177-187. doi:10.1007/s002690000141
Broadwell, K. S., Locatelli, M., Verlaguet, A., Agard, P., and Caddick, M. J. (2019). Transient and Periodic Brittle Deformation of Eclogites during IntermediateDepth Subduction. Earth Planet. Sci. Lett. 521, 91-102. doi:10.1016/j.epsl.2019. 06.008

Caddick, M. J., and Kohn, M. J. (2013). Garnet: Witness to the Evolution of Destructive Plate Boundaries. Elements 9, 427-432. doi:10.2113/gselements.9. 6.427

Chantel, J., Manthilake, G. M., Frost, D. J., Beyer, C., Ballaran, T. B., Jing, Z., et al. (2016). Elastic Wave Velocities in Polycrystalline Mg3Al2Si3O12-Pyrope Garnet to $24 \mathrm{GPa}$ and 1300 K. Am. Mineral. 101, 991-997. doi:10.2138/am2016-5335

Cisneros, M., Ashley, K. T., and Bodnar, R. J. (2020). Evaluation and Application of the Quartz-Inclusions-In-Epidote Mineral Barometer. Am. Mineral. 105, 1140-1151. doi:10.2138/am-2020-7379

Cruciani, G., Franceschelli, M., Scodina, M., and Puxeddu, M. (2019). Garnet Zoning in Kyanite-Bearing Eclogite from Golfo Aranci: New Data on the Early progradeP-Tevolution in NE Sardinia, Italy. Geol. J. 54, 190-205. doi:10.1002/ gj.3169

Dachs, E., Geiger, C. A., and Benisek, A. (2014). Thermodynamic Mixing Properties and Behavior of Grossular-Spessartine, (Ca Mn1-)3Al2Si3O12, Solid Solutions. Geochimica et Cosmochimica Acta 141, 294-302. doi:10. 1016/j.gca.2014.06.034

De Capitani, C., and Petrakakis, K. (2010). The Computation of Equilibrium Assemblage Diagrams with Theriak/Domino Software. Am. Mineral. 95, 1006-1016. doi:10.2138/am.2010.3354

Dera, P., Zhuravlev, K., Prakapenka, V., Rivers, M. L., Finkelstein, G. J., GruborUrosevic, O., et al. (2013). High Pressure Single-Crystal Micro X-Ray Diffraction Analysis with GSE_ADA/RSV Software. High Press. Res. 33, 466-484. doi:10.1080/08957959.2013.806504

Du, W., Clark, S. M., and Walker, D. (2016). Excess Mixing Volume, Microstrain, and Stability of Pyrope-Grossular Garnets. Am. Mineral. 101, 193-204. doi:10. 2138/am-2016-5128

Du, W., Clark, S. M., and Walker, D. (2015). Thermo-Compression of PyropeGrossular Garnet Solid Solutions: Non-Linear Compositional Dependence. Am. Mineral. 100, 215-222. doi:10.2138/am-2015-4752

Enami, M., Nishiyama, T., and Mouri, T. (2007). Laser Raman Microspectrometry of Metamorphic Quartz: A Simple Method for Comparison of Metamorphic Pressures. Am. Mineral. 92, 1303-1315. doi:10.2138/am.2007.2438

Fan, D., Fu, S., Yang, J., Tkachev, S. N., Prakapenka, V. B., and Lin, J.-F. (2019a). Elasticity of Single-Crystal Periclase at High Pressure and Temperature: The Effect of Iron on the Elasticity and Seismic Parameters of Ferropericlase in the Lower Mantle. Am. Mineral. 104, 262-275. doi:10.2138/am-2019-6656

Fan, D., Kuang, Y., Xu, J., Li, B., Zhou, W., and Xie, H. (2017). Thermoelastic Properties of Grossular-Andradite Solid Solution at High Pressures and Temperatures. Phys. Chem. Minerals 44, 137-147. doi:10.1007/s00269-0160843-4

Fan, D., Li, B., Chen, W., Xu, J., Kuang, Y., Ye, Z., et al. (2018). Research Progress of the Equation of State for Garnet Minerals. Chin. J. High Press Phys. 32, 1-13. doi:10.11858/gywlxb.20170597

Fan, D. W., G. Zhou, W., Liu, C. Q., Liu, Y. G., Wan, F., Xing, Y. S., et al. (2009). The Thermal Equation of State of (Fe0.86Mg0.07Mn0.07)3Al2Si3O12 Almandine. Mineral. Mag. 73, 95-102. doi:10.1180/minmag.2009.073.1.95

Fan, D., Xu, J., Lu, C., Tkachev, S. N., Li, B., Ye, Z., et al. (2019b). Elasticity of Singlecrystal Low Water Content Hydrous Pyrope at High-Pressure and HighTemperature Conditions. Am. Mineral. 104, 1022-1031. doi:10.2138/am2019-6897

Fan, D., Xu, J., Ma, M., Liu, J., and Xie, H. (2015). P-V-T Equation of State of Spessartine-Almandine Solid Solution Measured Using a Diamond Anvil Cell and In Situ Synchrotron X-ray Diffraction. Phys. Chem. Minerals 42, 63-72. doi:10.1007/s00269-014-0700-2

Fan, D., Zhou, W., Wei, S., Liu, Y., Ma, M., and Xie, H. (2010). A Simple External Resistance Heating Diamond Anvil Cell and its Application for Synchrotron Radiation X-ray Diffraction. Rev. Scientific Instr. 81, 053903. doi:10.1063/1. 3430069

Fei, Y., Ricolleau, A., Frank, M., Mibe, K., Shen, G., and Prakapenka, V. (2007). Toward an Internally Consistent Pressure Scale. Proc. Natl. Acad. Sci. 104, 9182-9186. doi:10.1073/pnas.0609013104 
Gatta, G. D., Merlini, M., Lee, Y., and Poli, S. (2011). Behavior of Epidote at High Pressure and High Temperature: a Powder Diffraction Study up to $10 \mathrm{GPa}$ and 1,200 K. Phys. Chem. Minerals 38, 419-428. doi:10.1007/s00269-010-0415-y

Geiger, C. A. (2013). Garnet: A Key Phase in Nature, the Laboratory, and Technology. Elements 9, 447-452. doi:10.2113/gselements.9.6.447

Geiger, C., and Rossman, G. (1994). Crystal Field Stabilization Energies of Almandine-Pyrope and Almandine-Spessartine Garnets Determined by FTIR Near Infrared Measurements. Phys. Chem. Minerals 21, 516-525. doi:10.1007/BF00203926

Gonzalez, J. P., Thomas, J. B., Baldwin, S. L., and Alvaro, M. (2019). Quartz-inGarnet and Ti-in-Quartz Thermobarometry: Methodology and First Application to a Quartzofeldspathic Gneiss from Eastern Papua New Guinea. J. Metamorph. Geol. 37, 1193-1208. doi:10.1111/jmg.12508

Gonzalez-Platas, J., Alvaro, M., Nestola, F., and Angel, R. (2016). EosFit7-GUI: A New Graphical User Interface for Equation of State Calculations, Analyses and Teaching. J. Appl. Cryst. 49, 1377-1382. doi:10.1107/S1600576716008050

Guiraud, M., and Powell, R. (2006). P-V-T Relationships and Mineral Equilibria in Inclusions in Minerals. Earth Planet. Sci. Lett. 244, 683-694. doi:10.1016/j.epsl. 2006.02.021

Gwanmesia, G. D., Zhang, J., Darling, K., Kung, J., Li, B., Wang, L., et al. (2006). Elasticity of Polycrystalline Pyrope (Mg3Al2Si3O12) to $9 \mathrm{GPa}$ and $1000^{\circ} \mathrm{C}$. Phys. Earth Planet. Interiors 155, 179-190. doi:10.1016/j.pepi.2005.10.008

Hartwig, J., and Galkin, V. (2021). Heat Capacity, Thermal Expansion, and Elastic Parameters of Pyrope. J. Therm. Anal. Calorim. 144, 71-79. doi:10.1007/ s10973-020-09396-2

Hazen, R. M., Downs, R. T., Conrad, P. G., Finger, L. W., and Gasparik, T. (1994). Comparative Compressibilities of Majorite-Type Garnets. Phys. Chem. Minerals 21, 344-349. doi:10.1007/BF00202099

Helffrich, G., and Connolly, J. A. D. (2009). Physical Contradictions and Remedies Using Simple Polythermal Equations of State. Am. Mineral. 94, 1616-1619. doi:10.2138/am.2009.3262

Holland, T. J. B., and Powell, R. (2011). An Improved and Extended Internally Consistent Thermodynamic Dataset for Phases of Petrological Interest, Involving a New Equation of State for Solids. J. Metamorph. Geol. 29, 333-383. doi:10.1111/j.1525-1314.2010.00923.x

Hu, Y., Wu, Z., Dera, P. K., and Bina, C. R. (2016). Thermodynamic and Elastic Properties of Pyrope at High Pressure and High Temperature by FirstPrinciples Calculations. J. Geophys. Res. Solid Earth 121, 6462-6476. doi:10. 1002/2016JB013026

Huang, S., and Chen, J. (2014). Equation of State of Pyrope-Almandine Solid Solution Measured Using a Diamond Anvil Cell and In Situ Synchrotron X-ray Diffraction. Phys. Earth Planet. Interiors 228, 88-91. doi:10.1016/.jpepi.2014.01.014

Jamtveit, B., Austrheim, H., and Putnis, A. (2016). Disequilibrium Metamorphism of Stressed Lithosphere. Earth-Science Rev. 154, 1-13. doi:10.1016/j.earscirev. 2015.12.002

Johnson, T. A., Cottle, J. M., and Larson, K. P. (2021). Delineation of Multiple Metamorphic Events in the Himalayan Kathmandu Complex, Central Nepal. J. Metamorph. Geol. 39 (4), 443-472. doi:10.1111/jmg.12583

Kantor, I., Prakapenka, V., Kantor, A., Dera, P., Kurnosov, A., Sinogeikin, S., et al. (2012). BX90: A New Diamond Anvil Cell Design for X-ray Diffraction and Optical Measurements. Rev. Scientific Instr. 83, 125102. doi:10.1063/1.4768541

Kohn, M. J. (2014). "Thermoba-Raman-try": Calibration of Spectroscopic Barometers and Thermometers for mineral Inclusions. Earth Planet. Sci. Lett. 388, 187-196. doi:10.1016/j.epsl.2013.11.054

Korsakov, A. V., Perraki, M., Zhukov, V. P., De Gussem, K., Vandenabeele, P., and Tomilenko, A. A. (2009). Is Quartz a Potential Indicator of Ultrahigh-Pressure Metamorphism? Laser Raman Spectroscopy of Quartz Inclusions in UltrahighPressure Garnets. Eur. J. Mineral. 21, 1313-1323. doi:10.1127/0935-1221/2009/ 0021-2006

Kosman, C. W., Kopylova, M. G., Stern, R. A., Hagadorn, J. W., and Hurlbut, J. F. (2016). Cretaceous Mantle of the Congo Craton: Evidence from Mineral and Fluid Inclusions in Kasai Alluvial Diamonds. Lithos 265, 42-56. doi:10.1016/j. lithos.2016.07.004

Kuang, Y., Xu, J., Li, B., Ye, Z., Huang, S., Chen, W., et al. (2019). Crystal-Chemical Properties of Synthetic Almandine-Pyrope Solid Solution by X-Ray SingleCrystal Diffraction and Raman Spectroscopy. Crystals 9, 541. doi:10.3390/ cryst9100541
Li, L., Weidner, D. J., Brodholt, J., Alfè, D., and Price, G. D. (2011). Ab Initio Molecular Dynamic Simulation on the Elasticity of Mg3Al2Si3O12 Pyrope. J. Earth Sci. 22, 169-175. doi:10.1007/s12583-011-0169-6

Liu, Q., Hermann, J., Zheng, S., and Zhang, J. (2020). Evidence for UHP Anatexis in the Shuanghe UHP Paragneiss from Inclusions in Clinozoisite, Garnet, and Zircon. J. Metamorph. Geol. 38, 129-155. doi:10.1111/jmg.12515

Mazzucchelli, M. L., Burnley, P., Angel, R. J., Morganti, S., Domeneghetti, M. C., Nestola, F., et al. (2018). Elastic Geothermobarometry: Corrections for the Geometry of the Host-Inclusion System. Geology 46, 231-234. doi:10.1130/ G39807.1

Mazzucchelli, M. L., Reali, A., Morganti, S., Angel, R. J., and Alvaro, M. (2019). Elastic Geobarometry for Anisotropic Inclusions in Cubic Hosts. Lithos 350351, 105218. doi:10.1016/j.lithos.2019.105218

Milani, S., Angel, R. J., Scandolo, L., Mazzucchelli, M. L., Ballaran, T. B., Klemme, S., et al. (2017). Thermo-Elastic Behavior of Grossular Garnet at High Pressures and Temperatures. Am. Mineral. 102, 851-859. doi:10. 2138/am-2017-5855

Milani, S., Nestola, F., Alvaro, M., Pasqual, D., Mazzucchelli, M. L., Domeneghetti, M. C., et al. (2015). Diamond-garnet Geobarometry: The Role of Garnet Compressibility and Expansivity. Lithos 227, 140-147. doi:10.1016/j.lithos. 2015.03.017

Moulas, E., Kostopoulos, D., Podladchikov, Y., Chatzitheodoridis, E., Schenker, F. L., Zingerman, K. M., et al. (2020). Calculating Pressure with Elastic Geobarometry: A Comparison of Different Elastic Solutions with Application to a Calc-Silicate Gneiss from the Rhodope Metamorphic Province. Lithos 378-379, 105803. doi:10.1016/j.lithos.2020.105803

Murri, M., Mazzucchelli, M. L., Campomenosi, N., Korsakov, A. V., Prencipe, M., Mihailova, B. D., et al. (2018). Raman Elastic Geobarometry for Anisotropic Mineral Inclusions. Am. Mineral. 103, 1869-1872. doi:10.2138/am-20186625CCBY

Nestola, F., Jung, H., and Taylor, L. A. (2017). Mineral Inclusions in Diamonds May Be Synchronous but Not Syngenetic. Nat. Commun. 8, 14168. doi:10.1038/ ncomms 14168

Nestola, F., Zaffiro, G., Mazzucchelli, M. L., Nimis, P., Andreozzi, G. B., Periotto, B., et al. (2019). Diamond-Inclusion System Recording Old Deep Lithosphere Conditions at Udachnaya (Siberia). Sci. Rep. 9, 1-8. doi:10.1038/s41598-01948778-x

Riches, A. J. V., Ickert, R. B., Pearson, D. G., Stern, R. A., Jackson, S. E., Ishikawa, A., et al. (2016). In Situ Oxygen-Isotope, Major-, and Trace-Element Constraints on the Metasomatic Modification and Crustal Origin of a Diamondiferous Eclogite from Roberts Victor, Kaapvaal Craton. Geochimica et Cosmochimica Acta 174, 345-359. doi:10.1016/j.gca.2015.11.028

Rivers, M., Prakapenka, V., Kubo, A., Pullins, C., Holl, C., and Jacobsen, S. (2008). The COMPRES/GSECARS Gas-Loading System for Diamond Anvil Cells at the Advanced Photon Source. High Press. Res. 28, 273-292. doi:10.1080/ 08957950802333593

Robinson, K., Gibbs, G. V., and Ribbe, P. H. (1971). Quadratic Elongation: A Quantitative Measure of Distortion in Coordination Polyhedra. Science 172, 567-570. doi:10.1126/science.172.3983.567

Roedder, E., and Bodnar, R. J. (1980). Geologic Pressure Determinations from Fluid Inclusion Studies. Annu. Rev. Earth Planet. Sci. 8, 263-301. doi:10.1146/ annurev.ea.08.050180.001403

Rosenfeld, J. L., and Chase, A. B. (1961). Pressure and Temperature of Crystallization from Elastic Effects Around Solid Inclusions in Minerals? Am. J. Sci. 259, 519-541. doi:10.2475/ajs.259.7.519

Shannon, R. D. (1976). Revised Effective Ionic Radii and Systematic Studies of Interatomic Distances in Halides and Chalcogenides. Acta Cryst. Sect A. 32, 751-767. doi:10.1107/s0567739476001551

Sinogeikin, S., Bass, J., Prakapenka, V., Lakshtanov, D., Shen, G., Sanchez-Valle, C., et al. (2006). Brillouin Spectrometer Interfaced with Synchrotron Radiation for Simultaneous X-ray Density and Acoustic Velocity Measurements. Rev. Scientific Instr. 77, 103905. doi:10.1063/1.2360884

Spear, F. S., and Wolfe, O. M. (2020). Revaluation of "Equilibrium" P-T Paths from Zoned Garnet in Light of Quartz Inclusion in Garnet (QuiG) Barometry. Lithos 372-373, 105650. doi:10.1016/j.lithos.2020.105650

Speziale, S., Duffy, T. S., and Angel, R. J. (2004). Single-Crystal Elasticity of Fayalite to 12 GPa. J. Geophys. Res. 109, 1-15. doi:10.1029/2004jb003162 
Tajčmanová, L., Manzotti, P., and Alvaro, M. (2021). Under Pressure: HighPressure Metamorphism in the Alps. Elements 17, 17-22. doi:10.2138/ gselements.17.1.17

Takahashi, T., and Liu, L.-G. (1970). Compression of Ferromagnesian Garnets and the Effect of Solid Solutions on the Bulk Modulus. J. Geophys. Res. 75, 5757-5766. doi:10.1029/JB075i029p05757

Vinet, P., Ferrante, J., Smith, J. R., and Rose, J. H. (1986). A Universal Equation of State for Solids. J. Phys. C: Solid State. Phys. 19, L467-L473. doi:10.1088/00223719/19/20/001

Vinograd, V. L., Sluiter, M. H. F., Winkler, B., Putnis, A., Hålenius, U., D. Gale, J., et al. (2004). Thermodynamics of Mixing and Ordering in Pyrope - Grossular Solid Solution. Mineral. Mag. 68, 101-121. doi:10.1180/ 0026461046810174

Wang, Y. B., Weidner, D. J., Zhang, J. Z., Gwanrnesia, G. D., and Liebermann, R. C. (1998). Thermal equation of state of garnets along the pyrope-majorite join. Phys. Earth Planet. Interiors 105, 59-71. doi:10.1016/S0031-9201(97)00072-1

Wolfe, O. M., and Spear, F. S. (2018). Determining the Amount of Overstepping Required to Nucleate Garnet during Barrovian Regional Metamorphism, Connecticut Valley Synclinorium. J. Metamorph. Geol. 36, 79-94. doi:10. 1111/jmg.12284

Xu, J., Zhang, D., Dera, P., Zhang, B., and Fan, D. (2017). Experimental Evidence for the Survival of Augite to Transition Zone Depths, and Implications for Subduction Zone Dynamics. Am. Mineral. 102, 1516-1524. doi:10.2138/am2017-5959

Xu, J., Zhang, D., Fan, D., Dera, P. K., Shi, F., and Zhou, W. (2019). Thermoelastic Properties of Eclogitic Garnets and Omphacites: Implications for Deep Subduction of Oceanic Crust and Density Anomalies in the Upper Mantle. Geophys. Res. Lett. 46, 179-188. doi:10.1029/2018gl081170

Zhang, H.-F., Zhou, M.-F., Sun, M., and Zhou, X.-H. (2010). The Origin of Mengyin and Fuxian Diamondiferous Kimberlites from the North China Craton: Implication for Palaeozoic Subducted Oceanic Slab-Mantle Interaction. J. Asian Earth Sci. 37, 425-437. doi:10.1016/j.jseaes.2009.10.006

Zhang, J., Martinez, I., Guyot, F., and Reeder, R. J. (1998a). Effects of Mg-Fe (Super 2+) Substitution in Calcite-Structure Carbonates; Thermoelastic Properties. Am. Mineral. 83, 280-287. doi:10.2138/am-1998-3-411

Zhang, L., Ahsbahs, H., Hafner, S. S., and Kutoglu, A. (1997). Single-Crystal Compression and Crystal Structure of Clinopyroxene up to $10 \mathrm{GPa}$. Am. Mineral. 82, 245-258. doi:10.2138/am-1997-3-402

Zhang, L., Ahsbahs, H., Kutoglu, A., and Geiger, C. A. (1999). Single-Crystal Hydrostatic Compression of Synthetic Pyrope, Almandine, Spessartine,
Grossular and Andradite Garnets at High Pressures. Phys. Chem. Minerals 27, 52-58. doi:10.1007/s002690050240

Zhang, L., Ahsbahs, H., and Kutoglu, A. (1998b). Hydrostatic Compression and Crystal Structure of Pyrope to $33 \mathrm{GPa}$. Phys. Chem. Minerals 25, 301-307. doi:10.1007/s002690050118

Zhang, Y. (1998). Mechanical and Phase Equilibria in Inclusion-Host Systems. Earth Planet. Sci. Lett. 157 (3-4), 209-222. doi:10.1016/S0012821X(98)00036-3

Zhong, X., Andersen, N. H., Dabrowski, M., and Jamtveit, B. (2019). Zircon and Quartz Inclusions in Garnet Used for Complementary Raman Thermobarometry: Application to the Holsnøy Eclogite, Bergen Arcs, Western Norway. Contrib. Mineral. Petrol. 174, 1-17. doi:10.1007/s00410019-1584-4

Zhong, X., Moulas, E., and Tajčmanová, L. (2020). Post-Entrapment Modification of Residual Inclusion Pressure and its Implications for Raman Elastic Thermobarometry. Solid Earth 11, 223-240. doi:10.5194/ se-11-223-2020

Zou, Y., Gréaux, S., Irifune, T., Whitaker, M. L., Shinmei, T., and Higo, Y. (2012). Thermal Equation of State of Mg3Al2Si3O12 Pyrope Garnet up to $19 \mathrm{GPa}$ and 1,700 K. Phys. Chem. Minerals 39, 589-598. doi:10.1007/s00269-012-0514-z

Conflict of Interest: BL, WG, and YZ were employed by PetroChina.

The remaining authors declare that the research was conducted in the absence of any commercial or financial relationships that could be construed as a potential conflict of interest.

Publisher's Note: All claims expressed in this article are solely those of the authors and do not necessarily represent those of their affiliated organizations, or those of the publisher, the editors, and the reviewers. Any product that may be evaluated in this article, or claim that may be made by its manufacturer, is not guaranteed or endorsed by the publisher.

Copyright (c) 2022 Li, Jiang, Xu, Tkachev, Ye, Huang, Guo, Zeng, Prakapenka, Fan and Zhou. This is an open-access article distributed under the terms of the Creative Commons Attribution License (CC BY). The use, distribution or reproduction in other forums is permitted, provided the original author(s) and the copyright owner(s) are credited and that the original publication in this journal is cited, in accordance with accepted academic practice. No use, distribution or reproduction is permitted which does not comply with these terms. 